\title{
Cysteine Substitution Mutants Give Structural Insight and Identify ATP Binding and Activation Sites at P2X Receptors
}

\author{
Jonathan A. Roberts and Richard J. Evans \\ Department of Cell Physiology and Pharmacology, University of Leicester, Leicester LE1 9HN, United Kingdom
}

\begin{abstract}
P2X receptors for extracellular ATP are a distinct family of ligand-gated cation channels involved in physiological processes ranging from synaptic transmission to muscle contraction. Common ATP binding motifs are absent from P2X receptors, and the extent of the agonist binding site is unclear. We used cysteine-scanning mutagenesis, radiolabeled 2-azido ATP binding, and methanethiosulfonate (MTS) compounds to identify amino acid residues involved in ATP binding and gating of the human P2X $\mathrm{X}_{1}$ receptor. The pattern of MTSEA [(2-aminoethyl)methanethiosulfonate hydrobromide] biotinylation was also used to determine the accessibility of substituted cysteine residues and whether this changed on addition of ATP. Analysis of cysteine-substituted mutants of the last 44 amino acid residues (S286 -I329) in the extracellular loop before the second transmembrane segment showed that N290, F291, R292, and K309 mutants had reduced ATP potency and 2-azido ATP binding. MTS reagents produced additional shifts in ATP potency at these residues, suggesting that they are directly involved in ATP binding; the effects were dependent on the charge of the MTS reagent at K309C; one explanation for this is that K309 interacts directly with the negatively charged phosphate of ATP. The remainder of the cysteine substitutions had little or no effect on ATP potency. However, at the mutants D316C, G321C, A323C, and I328C, MTS reagents did not change ATP potency but modified agonist-evoked responses, suggesting that this region may contribute to the gating of the channel.
\end{abstract}

Key words: ATP; P2X receptor; mutagenesis; binding; ion channels; agonist

\section{Introduction}

P2X receptors for ATP are ligand-gated cation channels and form from the homotrimeric or heterotrimeric assembly of seven different receptor subunits $\left(\mathrm{P}_{2} \mathrm{X}_{1-7}\right)$ to give a range of phenotypes (North, 2002). They are expressed widely in the nervous system and contribute to gut peristalsis (Ren et al., 2003), neuronal hypoxia reflexes (Rong et al., 2003), mechanotransduction (Cockayne et al., 2000), and pain sensation (Cockayne et al., 2000; Souslova et al., 2000; Tsuda et al., 2003; Chessell et al., 2005). P2X receptors do not contain common consensus ATP binding sequences [e.g., the Walker motif (Walker et al., 1982)] and the structure and organization of the binding site is unclear. A model incorporating four coordinates for ATP action at the $\mathrm{P} 2 \mathrm{X}_{1}$ receptor with positively charged lysines K68 and K309 coordinating binding of the phosphate tail of ATP and the adenine ring sandwiched between the domains incorporating phenylalanine (F) residues F185, T186 and N290, F291, and R292 with R292 coordinating the binding of the $\alpha$-phosphate has been proposed (Vial et al., 2004b). This model is supported by mutagenesis data from P2 $\mathrm{X}_{2}$ (Jiang et al., 2000; Clyne et al., 2002) and $\mathrm{P} 2 \mathrm{X}_{7}$ (Worthington et al., 2002) receptors. In the model, the residues associated with ATP binding are at least $18-20$ amino acids from the TM2

\footnotetext{
Received March 7, 2006; revised March 5, 2007; accepted March 5, 2007.

This work was supported by the Wellcome Trust. We thank Kelvin Agboh for contributions to the radiolabeling work, Rebecca Allsopp for helping with some of the Western blotting, and Helen Digby for discussion of the synapsin II model of ATP binding.

Correspondence should be addressed to Prof. Richard J. Evans, Department of Cell Physiology and Pharmacology, University of Leicester, University Road, Leicester LE1 9HN, UK. E-mail rje6@|e.ac.uk.

DOI:10.1523/JNEUROSCI.2310-06.2007

Copyright $\odot 2007$ Society for Neuroscience $\quad$ 0270-6474/07/274072-11\$15.00/0
}

(second transmembrane segment) region that forms part of the ion-conducting transmembrane pore of the channel. The model predicts that the region between K309 and the second transmembrane segment contributes to the transduction of agonist binding to channel gating. However, to substantiate models of the receptor, it is also important to consider the contribution of adjacent nonconserved residues. The variation in agonist potency and other pharmacological properties between P2X receptor subtypes indicates that nonconserved amino acid residues contribute to drug action at the receptor and may lead to subunit-specific localized changes in the agonist binding environment or channel properties. To further address the role of N290, F291, R292, $\mathrm{K} 309$, and adjacent nonconserved amino acid residues and the contribution of the 20 amino acid region before the second transmembrane segment, we have undertaken substituted cysteinescanning mutagenesis of the region S286-I329 of the human $\mathrm{P} 2 \mathrm{X}_{1}$ receptor. This approach has been used to study the structure of a range of ion channels and proteins (Akabas et al., 1992) including P2X receptors (Rassendren et al., 1997; Egan et al., 1998; Jiang et al., 2000, 2001; Haines et al., 2001) and the ATP binding site of Kir6.2 (Trapp et al., 2003). Analysis of effects of

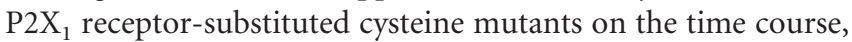
ATP potency, binding of radiolabeled 2-azido ATP, regulation by charged methanethiosulfonate (MTS) compounds (Akabas et al., 1992), and determination of the accessibility of residues in an $\mathrm{N}$-biotinylaminoethyl methanethiosulfonate (MTSEA-biotin) assay has allowed us to identify amino acid residues involved in ATP binding, channel properties, and information on the secondary structure of this section of the extracellular segment. 


\section{Materials and Methods}

Site-directed mutagenesis. Cysteine point mutations for residues S286I329 were introduced via the QuikChange mutagenesis kit (Stratagene, La Jolla, CA) using a human $\mathrm{P}_{2} \mathrm{X}_{1}$ receptor plasmid as the template, as described previously (Ennion et al., 2000). Production of the correct mutations and absence of coding errors in the $\mathrm{P} 2 \mathrm{X}_{1}$ mutant constructs was verified by DNA sequencing (Automated ABI Sequencing Service, University of Leicester).

Expression in Xenopus laevis oocytes. Wild-type (WT) and mutant constructs were transcribed to produce sense-strand cRNA (mMessage mMachine, Ambion, Austin, TX) as described previously (Ennion et al., 2000). Manually defolliculated stage V X. laevis oocytes were injected with $50 \mathrm{nl}(50 \mathrm{ng})$ of cRNA using an Inject+Matic microinjector (J. A. Gaby, Inject+Matic, Genéva, Switzerland) and stored at $18^{\circ} \mathrm{C}$ in ND96 buffer (in mм: $96 \mathrm{NaCl}, 2 \mathrm{KCl}, 1.8 \mathrm{CaCl}_{2}, 1 \mathrm{MgCl}_{2}, 5$ sodium pyruvate, and 5 HEPES, $\mathrm{pH}$ 7.6). The medium was changed daily before recording 3-7 d later.

Electrophysiological recordings. Two-electrode voltage-clamp recordings (at a holding potential of $-60 \mathrm{mV}$ ) were performed on cRNAinjected oocytes using a GeneClamp 500B amplifier with a Digidata 1322 analog-to-digital converter and pClamp 8.2 acquisition software (Molecular Devices, Menlo Park, CA), as described previously (Ennion et al., 2000). Native oocyte calcium-activated chloride currents in response to P2X receptor stimulation were reduced by replacing $1.8 \mathrm{~mm} \mathrm{CaCl}_{2}$ with $1.8 \mathrm{mM} \mathrm{BaCl}_{2}$ in the ND96 bath solution. ATP (Mg salt; Sigma, Poole, UK) was applied via a U-tube perfusion system. Because of the large size of oocytes, it is difficult to apply solutions rapidly. For desensitizing responses, this results in the true time course of the response being underestimated as a result of the relatively slow solution exchange and activation of responses. Experiments on nondesensitizing $\mathrm{P} 2 \mathrm{X}_{2}$ receptors expressed in oocytes indicate that $10-90 \%$ solution exchange takes $\sim 300-500 \mathrm{~ms}$ and means the rise times of $\mathrm{P} 2 \mathrm{X}_{1}$ currents $(\sim 100 \mathrm{~ms}$ for wild type) only give an indication of the speed of activation. The slower decay time of $\sim 1 \mathrm{~s}$ for P2X $\mathrm{X}_{1}$ WT currents is less likely to be affected by solution exchange and can be used to discriminate mutants with a change in time course. ATP $(0.01 \mu \mathrm{M}$ to $10 \mathrm{mM})$ was applied at 5 min intervals; using this regimen, reproducible ATP-evoked responses were recorded. Individual concentration-response curves were fitted with the Hill equation: $Y=\left[(X)^{\mathrm{H}} \times M\right] /\left[(X)^{\mathrm{H}}+\left(\mathrm{EC}_{50}\right)^{\mathrm{H}}\right]$, where $Y$ is the response, $X$ is the agonist concentration, $\mathrm{H}$ is the Hill coefficient, $M$ is the maximum response, and $\mathrm{EC}_{50}$ is the concentration of agonist evoking $50 \%$ of the maximum response. $\mathrm{pEC}_{50}$ is the $-\log _{10}$ of the $\mathrm{EC}_{50}$ value. Mutants that had considerably shifted ATP potency were tested with ATP concentrations up to $10 \mathrm{~mm}$. For the calculation of $\mathrm{EC}_{50}$ values, individual concentration-response curves were generated for each experiment, and statistical analysis was performed on the $\mathrm{pEC}_{50}$ data generated. In the figures, concentration-response curves are fitted to the mean normalized data.

Characterization of the effects of MTS compounds. To study the effect of MTS compounds on ATP activation at WT and cysteine mutants, ATP (approximate $\mathrm{EC}_{90-95}$ concentration) was applied, and either MTSEA or sodium (2-sulfonatoethyl) methanethiosulfonate (MTSES) (Toronto Research Chemicals, Toronto, Ontario, Canada) was bath perfused (for at least $5 \mathrm{~min}$, the recovery time required between application to see reproducible responses) before coapplication with ATP via the U-tube. This procedure should allow MTS reagents to bind to free cysteine residues in either the nonactivated (absence of ATP) or ligand-bound activated (presence of ATP) state. MTS reagents (1 mM) were made in ND96 solution immediately before use. The effect of MTS reagents on the concentration responses to ATP was investigated by application of ATP in the presence of MTS reagents, or after incubating oocytes overnight in MTS reagents, and the following day, ATP concentrations were applied via the U-tube with ND96 bathing solution (no MTS reagents present); the same results were found with either method.

2-Azido ATP and $P 2 X_{1}$ receptors; patch-clamp recordings from human embryonic kidney 293 cells expressing $P 2 X_{1}$ receptors. Human embryonic kidney 293 (HEK293) cells and HEK293 cells subcloned after transfection with the human WT $\mathrm{P} 2 \mathrm{X}_{1}$ receptor $\left(\mathrm{P}_{2} \mathrm{X}_{1} \mathrm{cl}-1\right.$ cells) were maintained in minimal essential medium with Earle's salts (with GlutaMAX I) sup- plemented with $10 \%$ fetal bovine serum and $1 \%$ nonessential amino acid (Invitrogen, Paisley, UK) at $37^{\circ} \mathrm{C}$ in a humidified atmosphere of $5 \% \mathrm{CO}_{2}$ and $95 \%$ air as described previously (Vial et al., 2004a). HEK293 cells were transiently transfected with mutant $\mathrm{P}_{2} \mathrm{X}_{1}$ receptors using LipofectAMINE 2000 reagent/Opti-MEM (Invitrogen). For patch-clamp studies, as a control to identify cells that were efficiently transfected, the pEGFP-N1 (Clontech, Cambridge, UK) vector (10\% of total plasmid transfected) was cotransfected with $\mathrm{P} 2 \mathrm{X}_{1}$ plasmids, and recordings were made only from fluorescent cells expressing the pEGFP. After $24 \mathrm{~h}$, the cells were plated onto glass coverslips and kept in culture for a maximum of $3 \mathrm{~d}$ for use in patch-clamp experiments. HEK293 cells expressing WT or mutant $\mathrm{P} 2 \mathrm{X}_{1}$ receptors were incubated in the presence of $1 \mu \mathrm{M} 2$-azido ATP (Affinity Labeling Technologies, Lexington, KY). They were then placed $7.5 \mathrm{~cm}$ from a UV light source (Uvitech LF206.MS; Flowgen, Ashby Park, Leicestershire, UK) on the $312 \mathrm{~nm}$ setting and illuminated three times for $2 \mathrm{~min}$ with gentle mixing by swirling between exposures. Any effects of UV illumination in the presence of 2-azido ATP on subsequent ATP-evoked $\mathrm{P}_{2} \mathrm{X}_{1}$ receptor-mediated currents were determined in whole-cell patch-clamp experiments as described previously (Vial and Evans, 2002). In preliminary studies, we showed that the UV irradiation protocol, in the presence or absence of ATP $(1 \mu \mathrm{M})$, had no effect on the peak amplitude of ATP $(1 \mu \mathrm{M})$-evoked $\mathrm{P}_{2} \mathrm{X}_{1}$ receptor currents.

${ }^{32} \mathrm{P} 2$-Azido ATP radiolabeling of the $P 2 X_{1}$ receptor. To assess the effects of mutations on agonist binding, we used a ${ }^{32} \mathrm{P}$ 2-azido ATP binding assay. We used this for wild type, F289C, a mutant with no change in ATP potency, and the five mutants with the greatest decrease in ATP potency (G288C, N290C, F291C, R292C, and K309C). Five oocytes injected with WT or mutant receptor cRNA were incubated in the presence of $1 \mu \mathrm{M}{ }^{32} \mathrm{P}$ 2-azido ATP (Affinity Labeling Technologies). They were then placed 7.5 $\mathrm{cm}$ from a UV light source (Uvitech LF206.MS; Flowgen) on the $312 \mathrm{~nm}$ setting and illuminated three times for 2 min with gentle mixing by swirling between exposures. Oocytes were washed in ice-cold PBS, lysed in $100 \mu$ l of buffer $\mathrm{H}$ [100 mm NaCl, 20 mm Tris-Cl, pH 7.4, 1\% Triton $\mathrm{X}-100$, and $10 \mu \mathrm{l} / \mathrm{ml}$ protease inhibitor mixture (P8340; Sigma)], and centrifuged for $2 \mathrm{~min}$ at $16,000 \times g$. Supernatant $(85 \mu \mathrm{l})$ was removed, and $0.9 \mu \mathrm{g}$ of anti-P2 $\mathrm{X}_{1}$ antibody (Alomone Labs, Jerusalem, Israel) was added and incubated for $1 \mathrm{~h}$ on ice (it is unlikely that 2-azido ATP binding to the extracellular segment interferes with anti- $\mathrm{P} 2 \mathrm{X}_{1}$ receptor binding, because the epitope for this antibody is the final 16 amino acid residues of the intracellular $\mathrm{C}$ terminus of the receptor). Thirty microliters of protein A-Sepharose $(40 \mathrm{mg} / \mathrm{ml}$; Amersham Biosciences, Buckinghamshire, UK) were added and incubated overnight with rolling at $4^{\circ} \mathrm{C}$. The Sepharose/antibody/protein complex was centrifuged for 2 min, and the beads were washed four times with buffer $\mathrm{H}$. After the final wash, the Sepharose pellet was resuspended in SDS sample buffer and heated to $95^{\circ} \mathrm{C}$ for $5 \mathrm{~min}$. Eluted $\mathrm{P} 2 \mathrm{X}_{1}$ receptors were loaded onto a $10 \%$ SDS-PAGE gel and run at $120 \mathrm{~V}$. After electrophoresis, the gel was dried overnight and exposed to Hyperfilm film (Amersham Biosciences) with an intensifying screen at $-80^{\circ} \mathrm{C}$ for 1 week, after which the film was developed. Densitometry analysis was performed on the resultant films with data corrected by background subtraction calculated for each lane and expressed as a percentage of wild type. We have assumed that the surface expression of wild type and the mutants used in the binding assay are equivalent because there were (1) no differences in the peak amplitude of ATP-evoked currents and (2) no differences in levels of total protein expression (see Fig. 2).

Western blotting. MTSEA-biotin was used to probe the various cysteine mutants to map the extracellular loop region S286-I329 of the P2X receptor. MTSEA-biotin reacts covalently with sulfhydryl groups provided by accessible cysteine residues. The WT $\mathrm{P}_{2} \mathrm{X}_{1}$ receptor contains no "free" cysteine residues (Ennion and Evans, 2002), and therefore an introduced cysteine would be free to bind MTS compounds if accessible.

Six oocytes injected with WT or mutant receptor cRNA were preincubated at room temperature for $30 \mathrm{~min}$ in $0.5 \mathrm{ml}$ of ND96 solution containing either $15 \mathrm{U} / \mathrm{ml}$ apyrase (type III, A7646; Sigma) or $1 \mathrm{~mm} \mathrm{ATP.}$ After the preincubation period, an additional $0.5 \mathrm{ml}$ of ND96 was added containing either $15 \mathrm{U} / \mathrm{ml}$ apyrase and $2 \mathrm{mM}$ MTSEA-biotin or $1 \mathrm{~mm}$ ATP and 2 mm MTSEA-biotin. Oocytes were incubated for an additional 30 min, after which they were washed twice in ND96 and lysed in buffer $\mathrm{H}$ at 
$20 \mu \mathrm{l}$ per oocyte, as described previously. Lysates were centrifuged at $16,000 \times g$ for $5 \mathrm{~min}$, and the cleared lysate was removed from the cell debris pellet. Ten microliters of cleared lysate (1/12th sample) were taken for total $\mathrm{P}_{2} \mathrm{X}_{1}$ protein analysis, and the remainder was mixed with $30 \mu \mathrm{l}$ of $4 \%$ streptavidin-agarose beads (S1638; Sigma) and rolled overnight at $4^{\circ} \mathrm{C}$. Beads were washed four times with buffer $\mathrm{H}$, after which $20 \mu \mathrm{l}$ of SDS-PAGE sample buffer was added to the beads and heated at $95^{\circ} \mathrm{C}$ for 5 min before loading on a $10 \%$ SDS-PAGE gel. Proteins were transferred to nitrocellulose, probed with $\mathrm{P} 2 \mathrm{X}_{1}$ primary antibody (1:1000; Alomone Labs) and secondary goat anti-rabbit antibody (A6154, 1:2500 dilution; Sigma), developed using ECL Plus (Amersham Biosciences), and exposed to Hyperfilm film (Amersham Biosciences). Densitometry analysis was performed on scanned images of the resultant films (ImageJ, http:// rsb.info.nih.gov/ij/). Analysis of $\mathrm{P}_{2} \mathrm{X}_{1} \mathrm{WT}$ and mutant MTSEAbiotinylated protein levels and the corresponding total $\mathrm{P}_{2} \mathrm{X}_{1}$ protein band were determined (corrected for background gel levels). The level of biotinylation was calculated for apyrase and ATP treatment and corrected for the total $\mathrm{P}_{2} \mathrm{X}_{1}$ receptor. For wild type, this was $0.58 \pm 0.09 \%$ and reflects not only the level of biotinylation but also the efficiency of the streptavidin purification steps. A threshold value of biotinylation was set as three times the WT level of biotinylation, and data are shown as fold biotinylation relative to this threshold. The level of biotinylation in the presence of ATP was also expressed as a percentage of the biotinylation in the presence of apyrase in paired samples, and any effects were determined using a Student's paired two-tailed $t$ test.

Analysis. All data are shown as mean \pm SEM. Significant differences between WT and mutant current amplitudes, time courses, agonist potency, and MTS reagent modification were calculated by one-way ANOVA, followed by Dunnett's test for comparisons of individual mutants against control using the SPSS 12.0 for Windows package (SPSS, Chicago, IL). The significance of any changes in ATP potency by MTS compounds and the effects of ATP on MTSEA biotinylation at particular mutants were determined with the appropriate Student's $t$ test. $n$ corresponds to the number of oocytes tested for electrophysiological data and the number of experiments for biochemical studies.

\section{Results}

\section{The effect of cysteine-scanning mutagenesis on human $\mathrm{P} 2 \mathrm{X}_{1}$} receptor ATP-mediated responses

To characterize the role of amino acid residues S286-I329 on ATP action at the $\mathrm{P} 2 \mathrm{X}_{1}$ receptor, we generated individual cysteine mutants and determined their effect on ATP potency (Fig. 1). WT human $\mathrm{P}_{2} \mathrm{X}_{1}$ receptors responded to ATP in a concentrationdependant manner $\left(\mathrm{EC}_{50}=\sim 0.9 \mu \mathrm{M}\right)$. Oocyte recordings provide only an approximation of the true $\mathrm{EC}_{50}$ because of the speed of solution exchanges and the non-steady-state nature of the desensitizing $\mathrm{P}_{2} \mathrm{X}_{1}$ receptor current. Cysteine substitution was well tolerated, and functional responses were recorded from all of the mutant channels. Cysteine substitution at positions R295 and R305 produced small currents to ATP $(10 \mathrm{~mm})$ of $16 \pm 4$ and $94 \pm 36 \mathrm{nA}$, respectively. R295C and R305C were poorly expressed at the cell surface, and they were unaffected by reducing agents (data not shown), suggesting the small amplitude of responses did not result from the formation of disulphide bonds; these mutants were not studied further. The point mutation R295A, however, had no effect on peak current amplitude or ATP potency $\left(\mathrm{pEC}_{50}=6.3 \pm 0.1\right)$, and we have previously shown that R305A has normal ATP potency (Ennion et al., 2000). The majority (33 of 44) of cysteine substitution mutants showed no significant change in ATP potency (Table 1). A modest twofold to threefold increase in ATP potency was seen for two mutants, L318C and G321C ( EC $_{50}$ values of $\left.\sim 0.3 \mu \mathrm{M}\right)$; previously, we have shown that the G321A mutation has no effect on ATP potency (Digby et al., 2005). Approximate 5-fold decreases in ATP potency were recorded for $\mathrm{F} 297 \mathrm{C}\left(\mathrm{EC}_{50}=4.8 \mu \mathrm{M}\right)$ and $\mathrm{F} 311 \mathrm{C}$ $\left(\mathrm{EC}_{50}=6.2 \mu \mathrm{M}\right)$, with $\sim 10$ - and $\sim 20$-fold decreases in potency
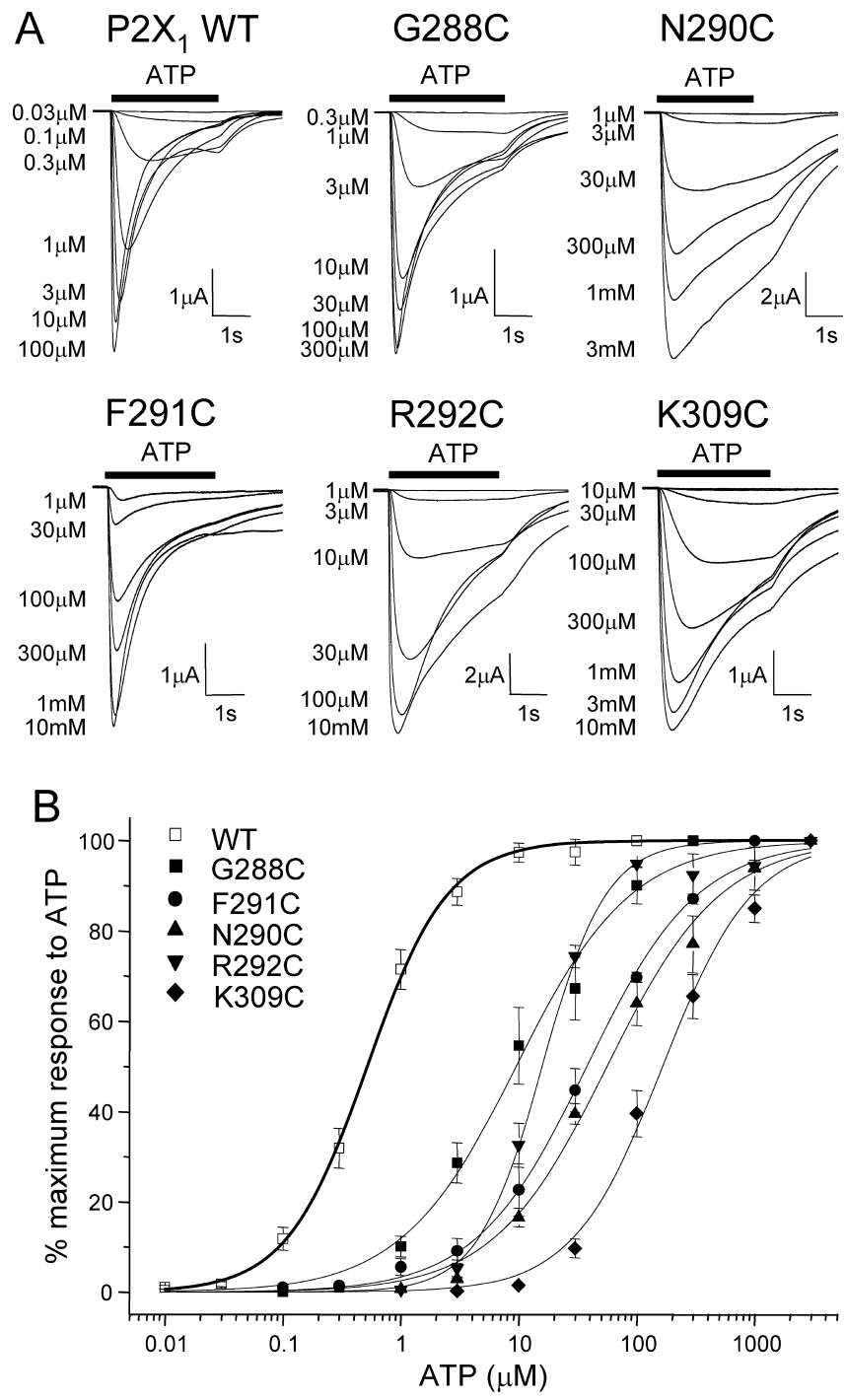

Figure 1. Effect of point cysteine $P 2 X_{1}$ mutations on ATP potency. ATP potency was tested on WT and P2X $\mathrm{X}_{1}$ receptor mutants expressed in oocytes by two-electrode voltage clamp (holding potential, $-60 \mathrm{mV}$ ). ATP application is indicated by bar. $A$, Trace data representative of currents observed for WT and mutant receptors in response to ATP applications at 5 min intervals. $\boldsymbol{B}$, Concentration-response curves to ATP for WT and mutants G288C, F291C, N290C, R292C, and K309C $(n=3-8)$. Error bars indicate SEM.

for $\mathrm{G} 288 \mathrm{C}\left(\mathrm{EC}_{50}=9.3 \mu \mathrm{M}\right)$ and $\mathrm{R} 292 \mathrm{C}\left(\mathrm{EC}_{50}=15 \mu \mathrm{M}\right)$. The largest change in ATP potency was at the mutants N290C, F291C, and $\mathrm{K} 309 \mathrm{C}$ with a $>50$-fold decrease in agonist potency $\left(\mathrm{EC}_{50}\right.$ values of 64,44 , and $175 \mu \mathrm{M}$, respectively) (Table 1, Fig. 1). For the mutants N290C and F291C, this reduction in potency was associated with a decrease in Hill slope $(1.3 \pm 0.1,0.9 \pm 0.1$, and $0.7 \pm 0.1$ for wild type and mutants, respectively; $p<0.01$ ); however, in contrast, the Hill slope was increased for the R292C mutant $(1.8 \pm 0.2 ; p<0.05)$.

A decrease in ATP potency could result from an effect on agonist binding and/or gating of the channel. To address this issue, we used a cross-linking assay with 2-azido ATP; this contains a photo-active azido $\left(-\mathrm{N}_{3}\right)$ group that is chemically inert until activation by UV light when a nitrene group is formed that reacts according to free-radical rules with any nearby part of the receptor. 2-Azido ATP is an agonist at the $\mathrm{P} 2 \mathrm{X}_{1}$ receptor, and on irradiation, a covalent linkage between the compound and the active site of the receptor is formed (given the desensitization of 
Table 1. Summary of the effects of cysteine substitution

\begin{tabular}{|c|c|c|}
\hline & $\mathrm{pEC}_{50}$ & Peak (nA) \\
\hline P2X1 WT & $6.1 \pm 0.1$ & $-8600 \pm 740$ \\
\hline S286C & $6.1 \pm 0.1$ & $-10,600 \pm 430$ \\
\hline P287C & $5.8 \pm 0.1$ & $-12,000 \pm 310^{*}$ \\
\hline G288C & $5.0 \pm 0.1^{* * * *}$ & $-10,600 \pm 380$ \\
\hline F289C & $6.3 \pm 0.2$ & $-11,000 \pm 350$ \\
\hline N290C & $4.2 \pm 0.1^{* * *}$ & $-8100 \pm 1400$ \\
\hline F291C & $4.4 \pm 0.1^{* * *}$ & $-9500 \pm 1200$ \\
\hline R292C & $4.8 \pm 0.1^{* * *}$ & $-9700 \pm 2200$ \\
\hline F293C & $5.7 \pm 0.1$ & $-10,000 \pm 580$ \\
\hline A294C & $6.0 \pm 0.1$ & $-10,700 \pm 1200$ \\
\hline R295C & ND & $-16 \pm 4^{* * *}$ \\
\hline H296C & $6.1 \pm 0.2$ & $-5400 \pm 810^{*}$ \\
\hline F297C & $5.3 \pm 0.1^{* * *}$ & $-8030 \pm 610$ \\
\hline V298C & $6.2 \pm 0.02$ & $-10,040 \pm 1200$ \\
\hline E299C & $6.3 \pm 0.1$ & $-9700 \pm 760$ \\
\hline N300C & $5.9 \pm 0.1$ & $-10,100 \pm 450$ \\
\hline G301C & $5.8 \pm 0.1$ & $-4900 \pm 480^{* *}$ \\
\hline T302C & $6.3 \pm 0.1$ & $-10,300 \pm 730$ \\
\hline N303C & $6.3 \pm 0.01$ & $-14,000 \pm 390^{* * * *}$ \\
\hline Y304C & $6.3 \pm 0.1$ & $-10,200 \pm 1100$ \\
\hline R305C & ND & $-94 \pm 36^{* * *}$ \\
\hline $\mathrm{H} 306 \mathrm{C}$ & $6.2 \pm 0.02$ & $-8400 \pm 470$ \\
\hline L307C & $6.2 \pm 0.04$ & $-7700 \pm 460$ \\
\hline F308C & $6.1 \pm 0.2$ & $-7600 \pm 400$ \\
\hline K309C & $3.8 \pm 0.1^{* * *}$ & $-7800 \pm 810$ \\
\hline V310C & $6.0 \pm 0.2$ & $-10,400 \pm 870$ \\
\hline F311C & $5.2 \pm 0.1^{* * *}$ & $-9900 \pm 750$ \\
\hline G312C & $5.7 \pm 0.2$ & $-9800 \pm 810$ \\
\hline I313C & $5.9 \pm 0.1$ & $-9300 \pm 940$ \\
\hline R314C & $5.8 \pm 0.2$ & $-8700 \pm 420$ \\
\hline F315C & $6.1 \pm 0.2$ & $-9200 \pm 690$ \\
\hline D316C & $5.7 \pm 0.1$ & $-10,900 \pm 1200$ \\
\hline I317C & $6.2 \pm 0.1$ & $-7300 \pm 880$ \\
\hline L318C & $6.5 \pm 0.1^{*}$ & $-7900 \pm 360$ \\
\hline V319C & $6.2 \pm 0.1$ & $-8300 \pm 780$ \\
\hline D320C & $5.7 \pm 0.01$ & $-9500 \pm 720$ \\
\hline G321C & $6.5 \pm 0.1^{*}$ & $-3200 \pm 960^{* * * *}$ \\
\hline K322C & $6.4 \pm 0.1$ & $-7000 \pm 390$ \\
\hline A323C & $5.9 \pm 0.2$ & $-7700 \pm 540$ \\
\hline G324C & $5.9 \pm 0.1$ & $-6900 \pm 250$ \\
\hline K325C & $6.4 \pm 0.04$ & $-7600 \pm 500$ \\
\hline F326C & $6.0 \pm 0.2$ & $-4800 \pm 330^{*}$ \\
\hline D327C & $6.1 \pm 0.04$ & $-5400 \pm 310^{*}$ \\
\hline I328C & $6.1 \pm 0.1$ & $-5800 \pm 360$ \\
\hline I329C & $6.2 \pm 0.1$ & $-6500 \pm 270^{*}$ \\
\hline
\end{tabular}

$\mathrm{pEC} \mathrm{C}_{50}$ values are shown as calculated from experimental data. $\mathrm{pEC} \mathrm{C}_{50}$ is $-\log _{10}$ of the $\mathrm{EC}_{50}$. Peak values were taken on first application of a maximal concentration of ATP [ for mutants with no change in ATP potency, this was $100 \mu \mathrm{M}$, a saturating concentration (see Fig. 1); for mutants with decreased ATP potency, this was $10 \mathrm{mM}]$. Conserved residues in five of seven P2X subtypes are highlighted in bold. ND, Not determined. ${ }^{*} p<0.05$; ${ }^{* *} p<0.01$; ${ }^{* * *} p<$ $0.001 . n=3-12$.

agonist-evoked responses in the continued presence of the agonist within 1-2 s, it is likely that 2-azido ATP cross-links to desensitized receptors). In ongoing studies on $\mathrm{P}_{2} \mathrm{X}_{1} \mathrm{WT}$ receptors expressed in HEK293 cells, we showed that UV irradiation, or incubation with $1 \mu \mathrm{M} 2$-azido ATP followed by a $>5$ min washout, has no effect on the amplitude of ATP-evoked currents (data not shown). However, UV irradiation in the presence of $1 \mu \mathrm{M}$ 2-azido ATP, followed by a $>5$ min washout, reduced subsequent ATP currents $(1 \mu \mathrm{M})$ by $\sim 60 \%$ (2277 \pm 588 and $770 \pm 270 \mathrm{pA}$ for control and UV irradiation in the presence of 2-azido ATP, respectively; $n=7$ for each; $p<0.05$ ). This indicates that the 2-azido ATP had cross-linked to the receptors, most likely locking them in an agonist-bound desensitized state, and blocked subsequent receptor activation. We therefore tested the effects of

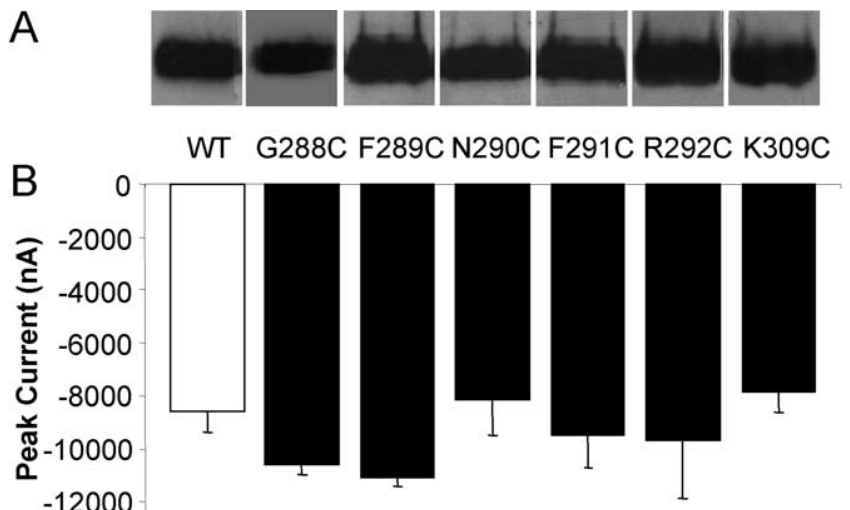

$-12000$

$-14000$

C WT G288C F289C N290C F291C R292C K309C

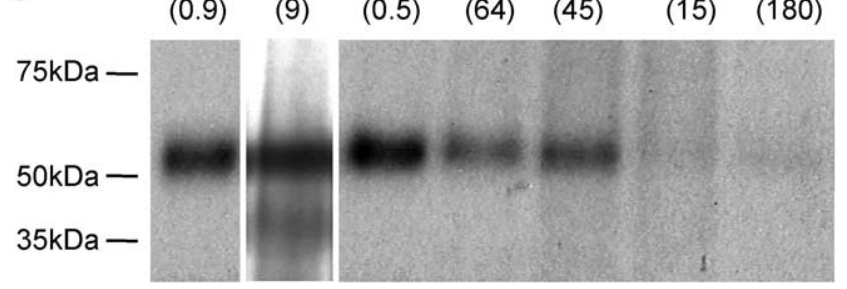

$\mathrm{D}$

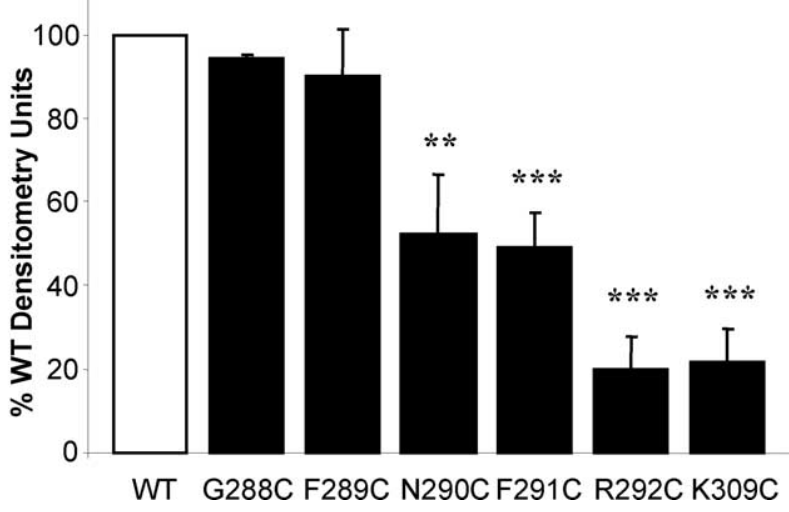

Figure 2. Effect of $P 2 X_{1}$ cysteine mutants on ${ }^{32} \mathrm{P} 2$-azido ATP binding. $A$, Total $P 2 X_{1}$ protein levels determined by Western blot analysis with $\mathrm{P} 2 \mathrm{X}_{1}$ antibody for WT and mutant receptors were similar. $\boldsymbol{B}$, Mean peak currents to ATP for WT and mutant receptors showing no significant differences in amplitude. $\boldsymbol{C}$, Autoradiograph depicting radiolabeled ${ }^{32} \mathrm{P} 2$ 2-azido ATP crosslinked to WT and mutant receptors [mean $\mathrm{EC}_{50}$ for ATP (in micromolars) is shown in parentheses]. D, Densitometric analysis of autoradiographs for ${ }^{32} \mathrm{P} 2$ 2-azido ATP cross-linked to WT and mutant receptors. Mutant $\mathrm{F} 289 \mathrm{C}$ (no change in $\mathrm{EC}_{50}$ ) shows no change in the level of crosslinked ${ }^{32}$ P2-azido ATP compared with wild type. ${ }^{* *} p<0.01 ;{ }^{* * *} p<0.001 ; n=6$. Error bars indicate SEM.

$1 \mu \mathrm{M}$ 2-azido ATP on ATP ( $\mathrm{EC}_{90}$ concentration)-evoked responses at the mutants G288C, N290C, F291C, R292C, and K309C. Irradiation in the presence of 2-azido ATP reduced by $\sim 55 \%$ the ATP response at G288C (2524 \pm 405 and $1158 \pm 308$ pA for control and 2-azido ATP irradiation; $n=9$ for each; $p<$ $0.05)$; this is a similar reduction as that of the WT and indicates there is little effect on 2-azido cross-linking to the G288C mutant channel (and consistent with the lack of effect of MTS reagents at this mutant; see below, Effects of MTS compounds on ATP responses at cysteine mutants). Irradiation in the presence of 2-azido ATP had no effect on the amplitude of subsequent responses to ATP at N290C, F291C, R292C, and K309C mutants (data not shown). These results suggest that there is a reduction in cross-linking of 2-azido ATP to the mutants N290C, F291C, 
ATP

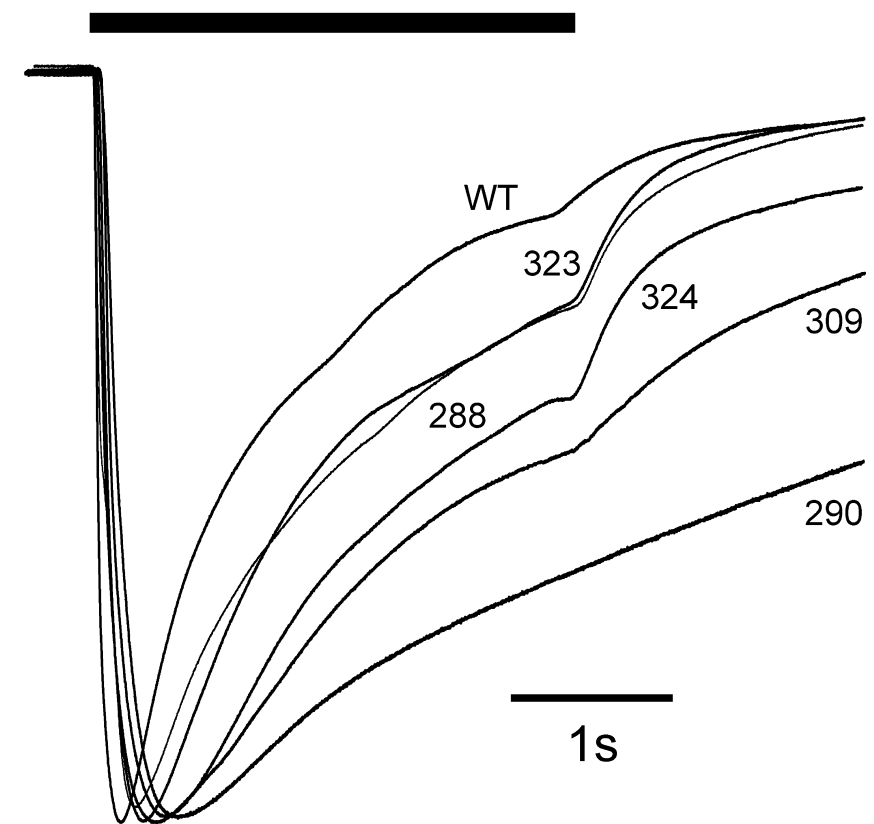

Figure 3. Effect of $P 2 X_{1}$ mutations to cysteine on the time course of ATP action. Representative recordings depicting the time course of $P 2 X_{1}$ receptor currents evoked in response to a maximal concentration of ATP (application period indicated by bar) for WT and mutants with an increased $\mathrm{EC}_{50}\left(\mathrm{G} 288 \mathrm{C}, \mathrm{N290C}\right.$, and $\mathrm{K309}$ ) or an unchanged $\mathrm{EC}_{50}$ ( $\mathrm{A323C}$ and $\mathrm{G324C}$ ) are shown.

R292C, and K309C and would be consistent with a decrease in agonist binding at these mutants. We therefore sought to test whether this could be measured directly using radiolabeled ${ }^{32} \mathrm{P}$ 2-azido ATP.

WT and mutant P2X receptors expressed in Xenopus oocytes were incubated with radiolabeled ${ }^{32} \mathrm{P} 2$-azido ATP and exposed to UV light. Oocytes were lysed, and $\mathrm{P} 2 \mathrm{X}_{1}$ receptors were immunoprecipitated (to remove background nonspecific binding), run on a gel, and exposed to film. Levels of 2-azido ATP binding were compared with wild type for the five mutants with the greatest shifts in ATP potency. The autoradiographs show a single band at $\sim 55 \mathrm{kDa}$ corresponding to $\mathrm{P}_{2} \mathrm{X}_{1}$ receptors. Wild type and the mutants had the same level of total $\mathrm{P} 2 \mathrm{X}_{1}$ receptor and peak amplitude currents (Fig. 2), indicating that the receptors are expressed at equivalent levels and a reduction in intensity of the band corresponds to a decrease in binding. Radiolabeling at wild type and the mutants G288C (10-fold decrease in ATP potency) and $\mathrm{F} 289 \mathrm{C}$ (no change in $\mathrm{ATP} \mathrm{EC}_{50}$ ) was detected at similar levels; in contrast, binding to the mutants N290C and F291C was reduced by $>50 \%$ and by $\sim 80 \%$ for R292C and K309C (Fig. 2). The lack of effect of the $\mathrm{G} 288 \mathrm{C}$ mutation on radiolabeling suggests that this cysteine substitution reduced ATP potency by an effect on the gating of the receptor (and this is consistent with the lack of modification by MTS reagents compared with adjacent the residues N290C, F291C, and R292C; see below). For the mutants N290C, F291C, R292C, and K309C, there is no simple relationship between the reduction in the amount of 2-azido ATP binding and the decrease in agonist potency at the receptors. The $\sim 80 \%$ reduction for $\mathrm{R} 292 \mathrm{C}$ and $\mathrm{K} 309 \mathrm{C}$ suggests that the change in potency at these receptors results predominantly from a decrease in agonist binding. The increase in Hill slope for the R292C mutant also indicates a contribution from effects on conformational changes and gating of the receptor. At N290C and F291C, although these showed a greater decrease in agonist potency than

\section{A R292C}

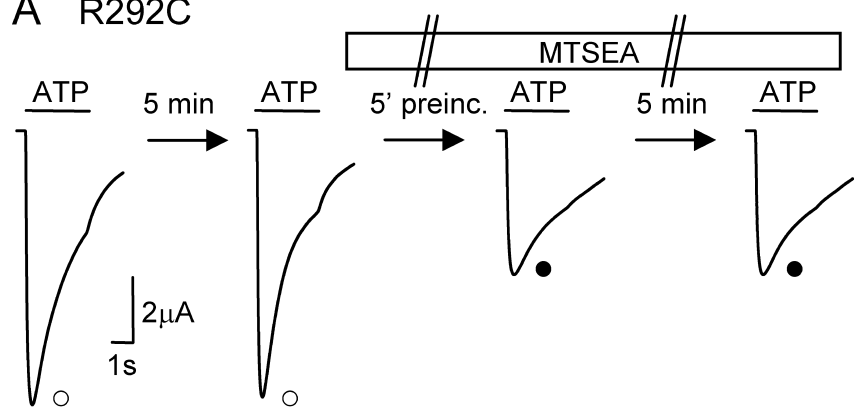

\section{B MTSEA}

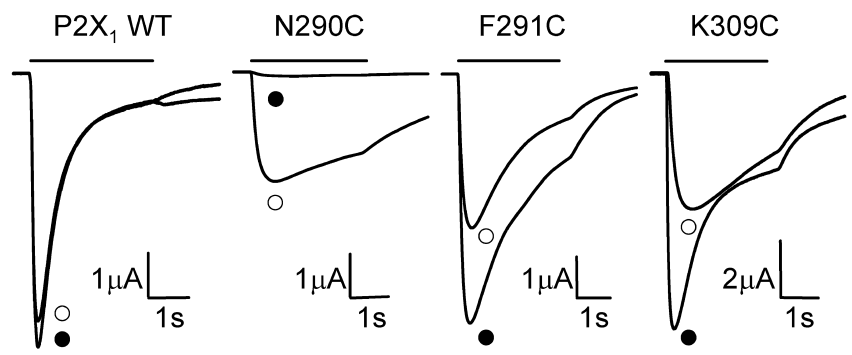

\section{MTSES}

P2X ${ }_{1}$ WT
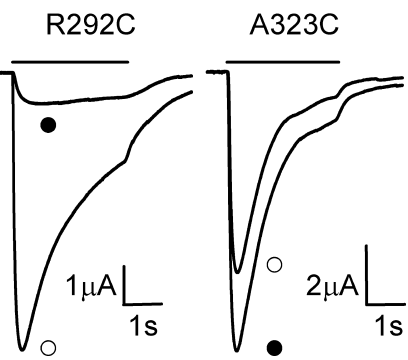

$\mathrm{K} 309 \mathrm{C}$
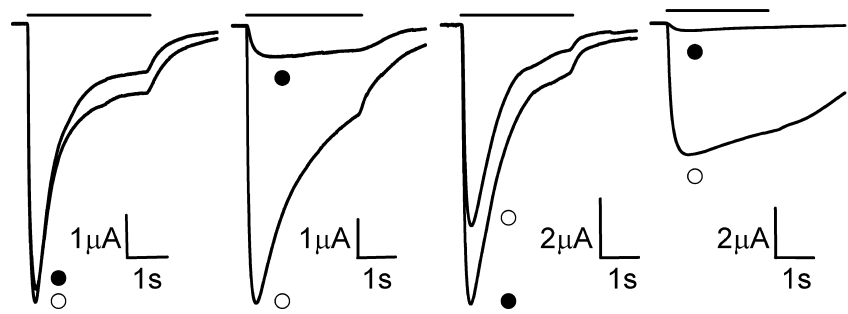

Figure 4. Effect of MTS compounds on ATP responses of P2X cysteine mutants. A, Protocol for testing of MTS compounds; at 5 min intervals, reproducible responses to ATP were recorded (open circles). The oocytes were then perfused with MTS reagent $(1 \mathrm{mM})$, and at 5 min intervals, ATP was coapplied with the MTS reagent (filled circle). The traces are shown for the R292C mutant and the application of MTSEA. $B$, Representative recordings of ATP-evoked responses from P2X ${ }_{1}$ wild type and the mutants N290C, F291C, and K309C under control conditions (open circles) and after application of MTSEA (filled circles; $1 \mathrm{~mm}$ for $5 \mathrm{~min}$ in the absence of ATP then coapplied with ATP). C, Representative recordings collected for P2X WT and mutants R292C, A323C, and K309C under control conditions (open circles) and following application of MTSES (filled circles; $1 \mathrm{~mm}$ for $5 \mathrm{~min}$ in the absence of ATP then coapplied with ATP).

R292C, they did not show as great a reduction in radioligand binding. The $\sim 40 \%$ reduction in 2 -azido ATP cross-linking and the decrease in Hill slope for the mutants N290C and F291C suggest that the reduction in their potency results from an $\sim 50 \%$ decrease in agonist binding and with the additional decrease in potency attributable to an effect on channel gating. These results show directly for the first time that mutation of residues N290, F291, R292, and K309 decreased agonist binding at P2X receptors.

WT P2X $\mathrm{X}_{1}$ receptor channels open rapidly and desensitize during the continued presence of ATP (time for the peak response to decay by $50 \%$ is $986 \pm 56 \mathrm{~ms}$ for responses to $100 \mu \mathrm{M}$ ATP, a maximal concentration). The time course of the response gives a measure of the transduction steps after agonist binding (i.e., channel gating), as does the deactivation step on washout of ATP. For the majority of cysteine substitutions, there was no change in the time course of decay of the response during continued ATP 


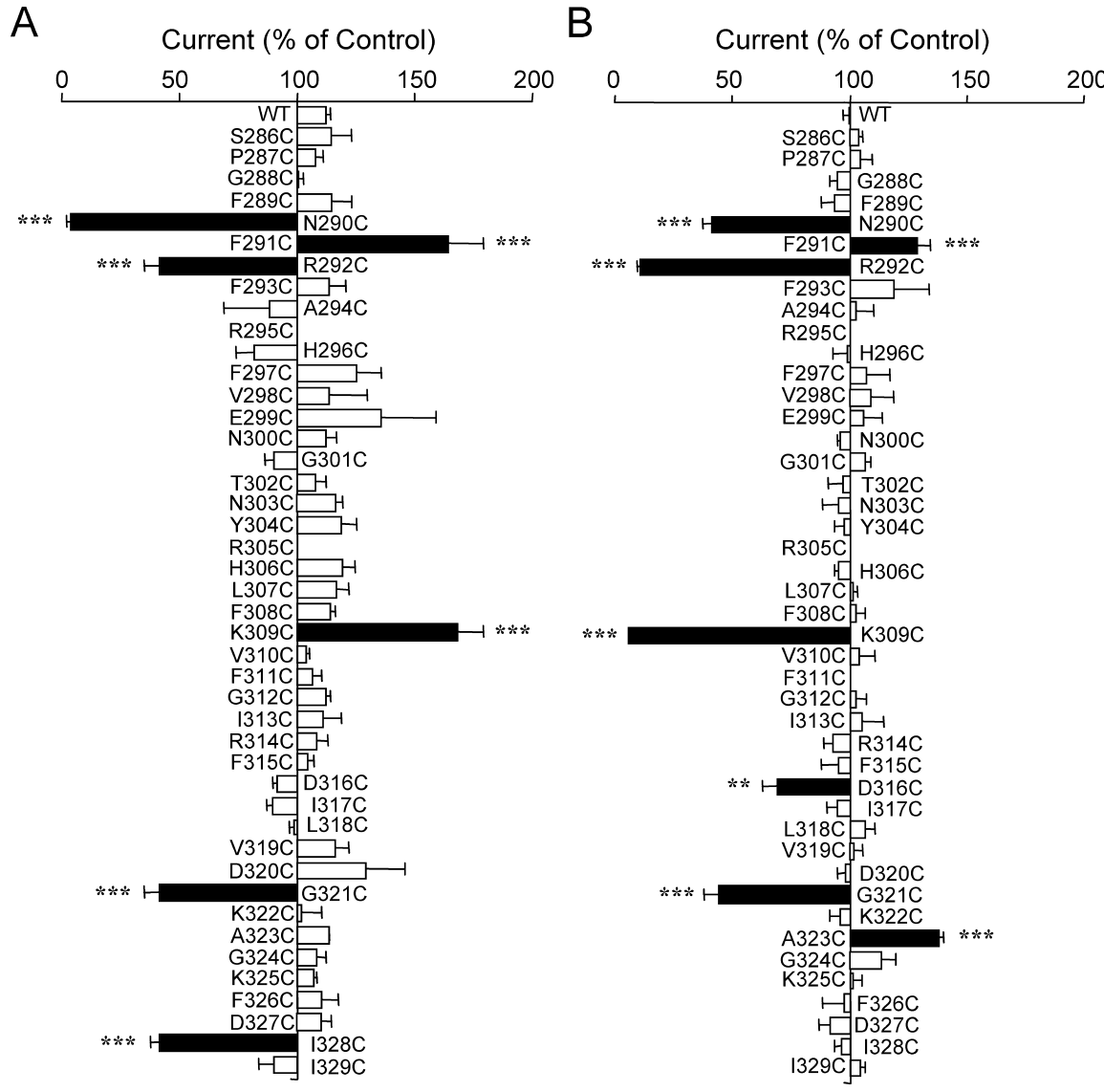

Figure 5. Summary of effects of MTS compounds on ATP responses of P2X $X_{1}$ cysteine mutants $A$, Effect of MTSEA (1 mM) on cysteine-scanning mutants $5286-$ I329 of the human P2X receptor $(n=3-4)$. B, Effect of MTSES (1 mM) on cysteine-scanning mutants S286-I329 of human P2X $(n=3-4) .{ }^{* *} p<0.01 ;{ }^{* * *} p<0.001$. Error bars indicate SEM.

any accessible cysteine residues either in the nonliganded (MTS reagent application in the absence of ATP) or ATP-bound (MTS reagent in the presence of ATP) receptors to be determined.

At WT P2X $\mathrm{X}_{1}$ receptors, ATP $(30 \mu \mathrm{M})$ evoked responses were potentiated slightly by positively charged MTSEA ( 1 $\mathrm{mM} ; 112 \pm 2 \%$ of the control response) (Figs. 4, 5). This effect is unlikely to be at a free cysteine residue in the receptor, because the 10 cysteine residues in the extracellular segment are considered to form five disulphide bonds (Clyne et al., 2002; Ennion and Evans, 2002), and is most likely to be a nonspecific effect. At the majority of cysteine mutants, MTSEA had no effect on the amplitude of responses compared with WT channels (Fig. 5). A reduction in the amplitude of ATP responses after MTSEA (1 mM) treatment was observed for the mutants N290C, R292C, G321C, and I328C (MTSEA reduced the responses to $4 \pm 2,42 \pm 7,41 \pm 7$, and $41 \pm 4 \%$ relative to the control ATP response, respectively) (Figs. 4, 5). In contrast, at mutants F291C and K309C, the addition of MTSEA potentiated ATPevoked responses to $164 \pm 15$ and $168 \pm$ $10 \%$ relative to control, respectively. In all cases, the maximal effects of MTSEA on the amplitude of ATP responses were seen in 5-10 min (one to two ATP applications; ATP was applied at 5 min intervals).

Negatively charged MTSES ( $1 \mathrm{~mm}$ ) had no effect on the amplitude of ATP-evoked

application (maximal ATP concentration). Mutants with a change in time course could be divided into two categories: (1) mutants G288C, N290C, and K309C with decreased ATP potency showed a prolongation in the decay of the evoked current $(2669 \pm 165,2907 \pm 158$, and $2198 \pm 353$, respectively); and (2) mutants A323C and G324C had no effect on ATP potency but doubled the decay time $(2125 \pm 281$ and $2022 \pm 212$, respectively) (Fig. 3). These results suggest that A323 and G324 contribute to the gating of the $\mathrm{P}_{2} \mathrm{X}_{1}$ receptor with mutation of these residues to cysteine leading to prolonged channel opening before entering the desensitized state.

\section{Effect of MTS compounds on ATP responses at cysteine mutants}

For $\mathrm{P} 2 \mathrm{X}$ receptors, the ability to introduce charge using MTS reagents may be a useful tool because (1) the ATP molecule has negative charge associated with the phosphate tail; (2) in physiological solutions, magnesium is complexed with ATP, resulting in localized positive charge; and (3) the channel is selective for cations. We have therefore tested the ability of positively charged MTSEA and negatively charged MTSES to modify ATP-evoked responses at WT and mutant $\mathrm{P}_{2} \mathrm{X}_{1}$ receptors. For these protocols following establishment of reproducible control responses, MTS reagents $(1 \mathrm{~mm})$ were applied for the $5 \mathrm{~min}$ between ATP applications as well as being coapplied with ATP (5 min is required between ATP applications to allow for recovery from receptor desensitization). This should allow the effects of MTS reagents at responses at $\mathrm{WT} \mathrm{P} 2 \mathrm{X}_{1}$ receptors (100 $\pm 3 \%$ of control response) and the majority of individual cysteine-substituted mutants (Figs. 4, 5). However, ATP responses at the mutants N290C, R292C, K309C, D316C, and G321C were all significantly inhibited by $1 \mathrm{~mm}$ MTSES $(41 \pm 4,10 \pm 1,6 \pm 0.2,69 \pm 6$, and $44 \pm$ $6 \%$ relative to the control ATP response, respectively). F291C and A323C were both significantly potentiated (129 \pm 5 and $138 \pm$ $2 \%$ relative to control, respectively). In all cases, the maximal effects of MTSES on the amplitude of ATP responses were seen in 5-10 min of MTSES application (ATP was applied at $5 \mathrm{~min}$ intervals).

The modification of some mutant $\mathrm{P}_{2} \mathrm{X}_{1}$ receptor responses highlights a contribution of these residues to ATP action at the receptor. The amplitude of $\mathrm{P} 2 \mathrm{X}_{1}$ responses could be regulated by a change in the ATP potency of the receptor and/or an effect on channel gating and ionic permeation. To establish whether a change in ATP potency was involved, we determined the effect of MTS reagents on the concentration-response curves. For this, MTS compounds were present in the superfusion solution and concomitantly applied with ATP. For mutants D316C $\left(\mathrm{pEC}_{50}=\right.$ $5.7 \pm 0.07$ and $5.9 \pm 0.22$ for control and MTSES, respectively) $\mathrm{G} 321 \mathrm{C}\left(\mathrm{pEC}_{50}=6.5 \pm 0.07,6.8 \pm 0.20\right.$, and $6.4 \pm 0.18$ for control, MTSEA, and MTSES, respectively), A323C $\left(\mathrm{pEC}_{50}=\right.$ $5.9 \pm 0.17$ and $6.1 \pm 0.05$ for control and MTSES, respectively), and $\mathrm{I} 328 \mathrm{C}\left(\mathrm{pEC}_{50}=6.1 \pm 0.15\right.$ and $6.2 \pm 0.13$ for control and MTSEA, respectively), the MTS compounds had no effect on ATP potency, demonstrating that at these mutants, the MTS 
compounds were not acting to interfere with ATP binding to the receptor but were having an effect on channel gating or ionic permeation. In contrast, at residues N290C, F291C, R292C, and K309C, MTS compounds changed the potency of ATP at the receptors. At N290C and R292C, MTSES and MTSEA decreased ATP potency by $\sim 18$ - and 5-fold, respectively $\left(p<0.005\right.$ for $\mathrm{pEC}_{50}$ values $)$, whereas MTSEA potentiates at F291C by 5 -fold $(p<0.005)$. The similar modulatory effects of positively charged MTSEA and negatively charged MTSES at N290C (inhibition), F291C (potentiation), and R292C (inhibition) receptors suggest that they result from the introduction of the bulk of the side groups and that localized charges at these residues do not contribute to ATP action. At K309C, the effects of the MTS compounds were dependent on the charge. ATP potency was increased $\sim 20$ fold after incubation with positively charged MTSEA (the MTSEA-modified cysteine residue is of similar size and charge to the lysine residue and has been used to rescue function of a lysine mutation in the intracellular domain of the $\mathrm{P}_{2} \mathrm{X}_{4}$ receptor (Fountain and North, 2006) ( $p<0.0005$ for $\mathrm{pEC}_{50}$ values), and responses even to a maximal concentration of ATP $(10 \mathrm{~mm})$ were abolished by negatively charged MTSES. This suggests that a charge at position $\mathrm{K} 309$ is important for mediating the binding of ATP. MTS reagents react irreversibly with cysteine residues, and overnight incubation with MTS compounds had the same effects on ATP potency as bath application (Fig. 6) and can be used to reduce the amount of costly MTS reagents used.

MTSEA-biotin accessibility at P2 $\mathrm{X}_{1}$ WT and cysteine mutants

MTS compounds have identified substituted cysteine residues that contribute to ATP action at the $\mathrm{P}_{2} \mathrm{X}_{1}$ receptor. For residues in which MTS compounds have no effect, it is unclear whether this is because the residue does not contribute to the actions of ATP at the receptor or whether the residue is inaccessible. To help discriminate between these two possibilities, and gain some experimental evidence for the secondary structure of the extracellular loop, we have determined directly whether MTSEAbiotin reacts with individual cysteine point mutants of the $\mathrm{P} 2 \mathrm{X}_{1}$ receptor. The MTSEA-

biotin molecule is like a ball and chain with an $\sim 0.5 \times 0.7 \mathrm{~nm}$ planar head group, and the reactive disulphide is near the end of a flexible chain $(\sim 1.7 \times 0.5 \mathrm{~nm})$ incorporating the MTSEA $(\sim 1.0 \times 0.5 \mathrm{~nm}$; estimated using SwissPDBViewer). Residues that react with MTSEA-biotin must therefore be accessible through an opening at
A
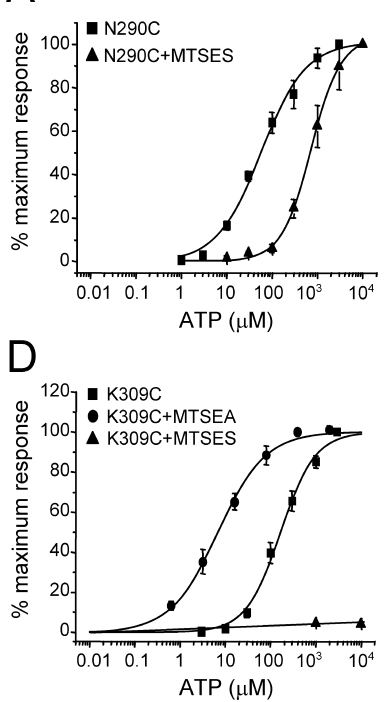

B

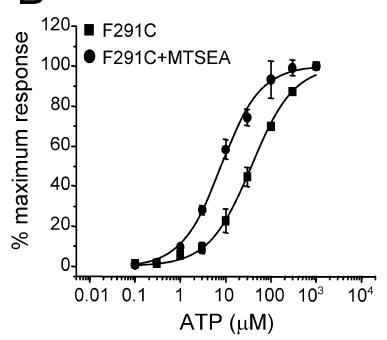

E $\quad F$
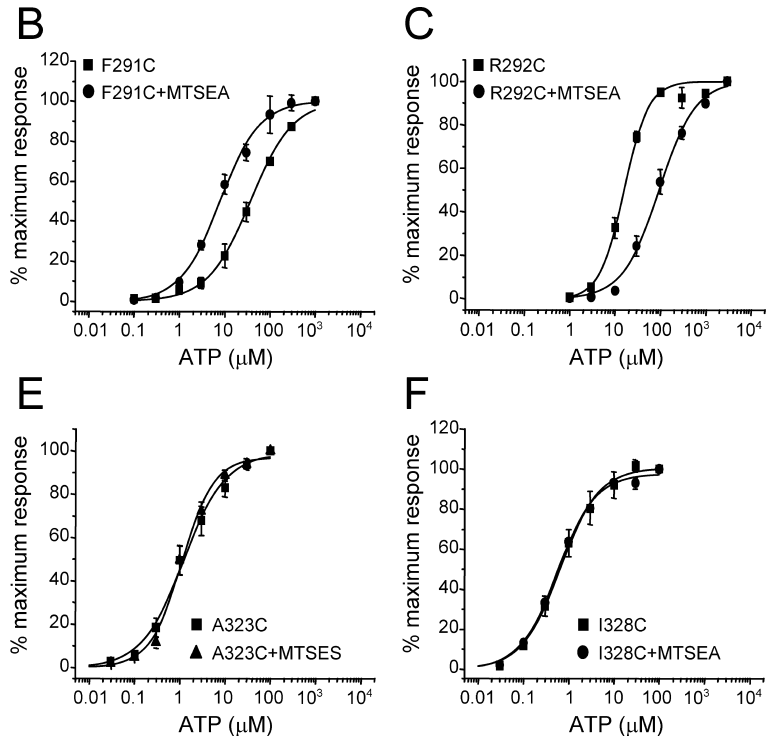

Figure 6. Effect of MTS compounds on ATP potency at cysteine mutants. $\boldsymbol{A}$, At N290C, MTSES decreased ATP potency. $\boldsymbol{B}$, At F291C, MTSEA (1 mm) application increases ATP potency. C, At R292C, ATP potency was decreased by overnight incubation with MTSEA (1 mm). D, Overnight incubation with MTSEA (positive charge, $1 \mathrm{~mm}$ ) increased ATP potency at K309C, whereas overnight incubation with MTSES (negative charge, $1 \mathrm{~mm}$ ) abolished the response. $\boldsymbol{E}, \boldsymbol{F}$, At A323C and I328C, ATP potency is unaffected by incubation with MTSES and MTSEA, respectively ( $1 \mathrm{~mm}$ for each; $n=3-6$ ). Data are shown for overnight incubations with MTS reagent that gave the same results as bath-applied MTS reagents. Error bars indicate SEM.

\section{WT}
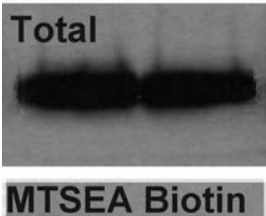

N290C
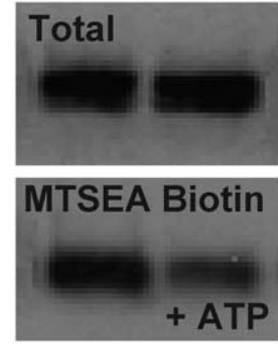

F325C
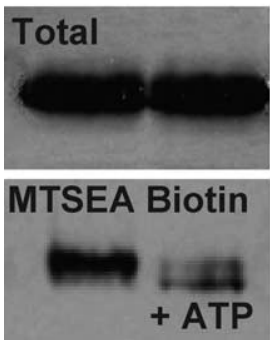
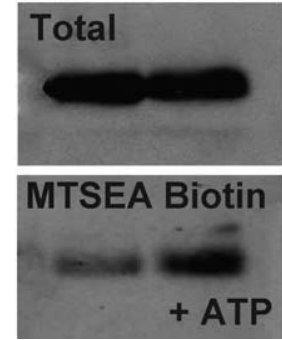
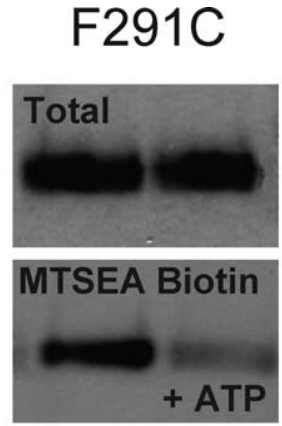

G301C
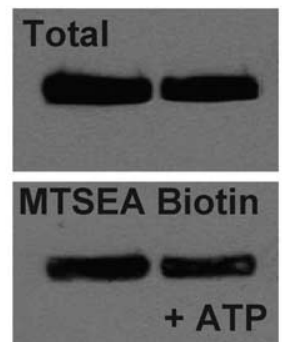
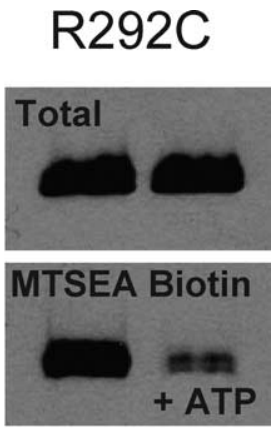

T302C

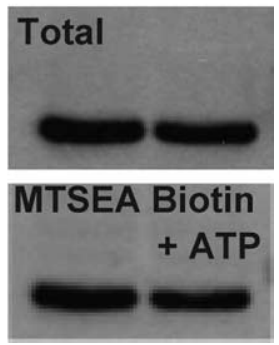

Figure 7. MTSEA-biotin labeling of mutant and WTP2X 2 receptors. Oocytes expressing WT and mutant $P 2 X_{1}$ receptors were incubated in MTSEA-biotin, which biotinylates free cysteine residues. Biotin-labeled proteins were isolated with streptavidin-agarose beads, and the resultant proteins were run on SDS-PAGE, blotted for $\mathrm{P}_{2} \mathrm{X}_{1}$ receptor, and compared with total levels of receptor expression. In control conditions, apyrase was added to break down any endogenously released ATP. The degree of MTSEA biotinylation was also determined in the presence of ATP. There is a reduction in the molecular mass of $\mathrm{T} 302 \mathrm{C}$ because this mutation removes a consensus sequence for glycosylation (N300G301T302); a similar reduction was also seen for N300C (not shown).

least $0.5 \mathrm{~nm}$ in diameter and $>2.2 \mathrm{~nm}$ deep widening to at least 0.7 $\mathrm{nm}$ (to incorporate the biotin). MTSEA-biotin can be used to differentiate water-exposed cysteines from cysteines buried within a protein structure, because only the water-exposed cysteines react at an appreciable rate. 
MTSEA biotinylation was detected by Western blotting with an anti- $\mathrm{P}_{2} \mathrm{X}_{1}$ receptor antibody after isolation of biotinylated proteins with streptavidin-agarose beads (Fig. 7); any endogenous ATP released from the oocytes was broken down by incubations in the presence of apyrase. At WT P2X $\mathrm{X}_{1}$ receptors, very low levels of biotinylated protein were detected as reported previously (Ennion and Evans, 2002), consistent with the 10 cysteine residues in the extracellular loop forming five disulphide bonds (Clyne et al., 2002; Ennion and Evans, 2002). A threshold for positive biotinylation was set at more than three times the WT background level (Figs. 7, 8). For the majority of substituted cysteine residues (36 of 42), MTSEA biotinylation was detected above threshold, demonstrating that these substituted cysteine residues are accessible at the receptor surface. For N300CT302C, this corresponds to a site of golgi-mediated glycosylation consistent with surface accessibility (Rettinger et al., 2000; Roberts and Evans, 2006). The degree of biotinylation was dependent on the position of substitution, indicating that the local environment or accessibility is variable across this region of the receptor. We also determined whether the level of biotinylation was changed by stimulation with ATP (Figs. 7, 8).

ATP reduced MTSEA biotinylation for cysteine-substituted residues in the regions S286-E299, Y304, F308C-D316C, and L318-D320. In these cases (with the exception of N290F291R292 and K309 cysteine mutants), there was little or no effect on ATP potency. One explanation for these changes in MTSEA biotinylation could be that localized charge in the binding pocket associated with the bound ATP interfered with MTSEA biotinylation. However, when either positively (MTSEA) or negatively charged (MTSES) reagents are applied to these mutants, they had no effect on ATP potency (supporting that they do not contribute directly to the agonist binding site) and suggest that at these positions, ATP does not directly interfere with MTSEA biotinylation. An alternative is that the decrease in MTSEA biotinylation at these residues results from a conformational change in the extracellular loop of the $\mathrm{P}_{2} \mathrm{X}_{1}$ receptor associated with agonist binding making the substituted cysteine residues less accessible. A conformational change is also supported by the increase in MTSEA biotinylation in response to ATP for K325C, a residue close to the predicted pore region of the $\mathrm{P} 2 \mathrm{X}$ receptor channel. Such a conformational change associated with agonist binding could be similar to the "clam shell" closure of the agonist-binding pocket of ionotropic glutamate receptors (Jin et al., 2003). If the decrease in MTSEA biotinylation does result from a conformational change in the $\mathrm{P} 2 \mathrm{X}_{1}$ receptor, this gives us a first glimpse of how agonist binding leads to structural changes in the extracellular ligand-binding loop of the receptor. It is tempting to speculate that the lack of change by ATP application to MTSEA biotinylation in the region $\mathrm{N} 300 \mathrm{C}-\mathrm{N} 303 \mathrm{C}$ while the adjacent regions showed marked decreases suggests that this region could act as a stable point or hinge around which conformation changes occur bringing together or stabilizing the proximity of the N290F291R292 and K309 residues that we suggest contribute to the ATP binding site.

Barely above threshold levels of biotinylation were detected for H306C, R314C, G321C, A323C, and F326C (either in the presence or absence of ATP), suggesting that there is restricted accessibility of MTSEA-biotin at these positions. Very low levels equivalent to wild type were detected for K322C (either in the presence or absence of ATP), indicating that this residue is buried within the protein or MTSEA is unable to bind. Overall, the MTSEA biotinylation results indicate regions of the extracellular loop that are readily accessible on the surface of the protein can be used to develop models of the extracellular segment of the recep-

\section{MTSEA biotinylation (fold over threshold)}

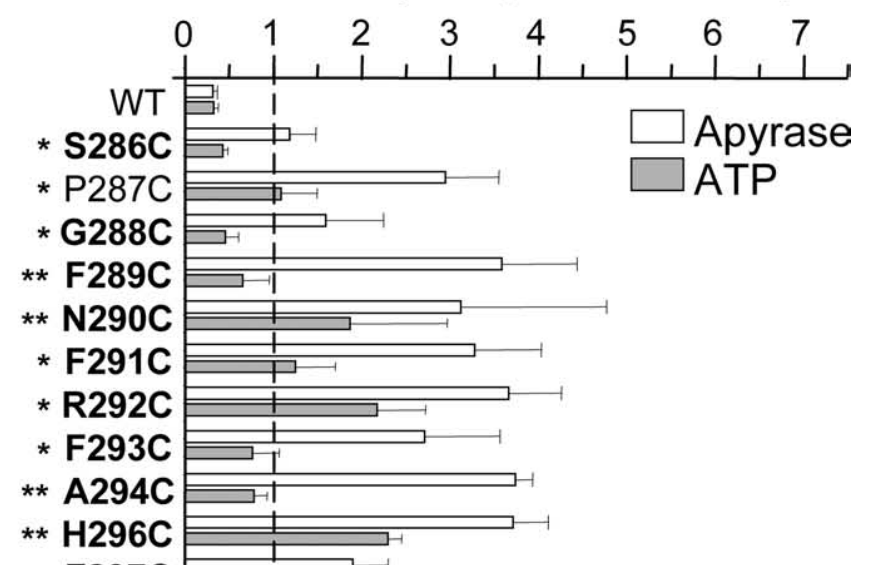

* F297C

** V298C

* E299C

N300C

G301C

T302C

N303C

* Y304C

H306C

L307C

* F308C

* K309

* V310C

* F311C

* G312

** I 313C

* R314C

** F315C

* D316C

I317C

** L318C

** V319C

*** D320C

G321C

K322C

A323C

G324C

* K325C

F326C

D327C

I328C

I329C
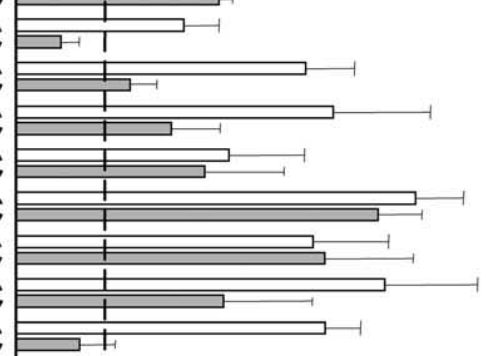

एक
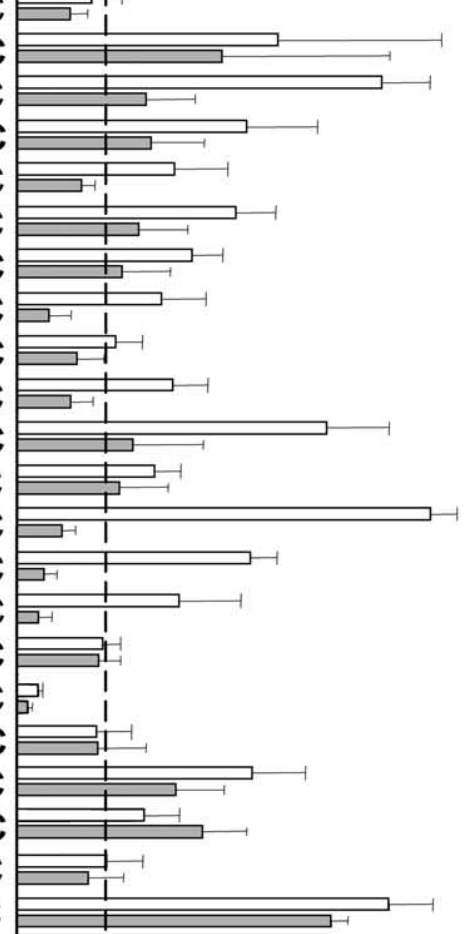

\section{I329C}

Figure 8. Summary of MTSEA-biotin labeling of P2X $X_{1}$ mutants and WT receptor and the effects of ATP stimulation. A summary of the level of MTSEA biotinylation in the presence of apyrase and ATP is shown. MTSEA biotinylation was calculated as the biotinylation intensity expressed as the percentage of total $P 2 X_{1}$ receptor levels (for wild type or the particular mutant) from expression in the same batch of oocytes. A threshold for biotinylation is shown (dashed line) at more than threefold the basal WT level. Significant changes in the level of biotinylation in response to ATP application were determined with the paired Student's $t$ test. ${ }^{*} p<0.05$; ${ }^{* *} p<0.01 ;{ }^{* * *} p<0.001 ; n=3-5$. Residues in bold are conserved in at least five of the human $P 2 X$ receptor subunits. Error bars indicate SEM. 
tor and give an insight into conformational changes after receptor activation.

\section{Discussion}

The majority of cysteine mutants of the 44 amino acids before the second transmembrane segment had little ( 4 mutants) or no (33 mutants) effect on ATP potency and were unaffected by MTS reagents. Several of these mutants react with MTSEAbiotin, indicating their accessibility, but MTSEA had no effect on ATP responses (Fig. 9). This allows us to exclude an essential role of these residues in mediating ATP action at the $\mathrm{P} 2 \mathrm{X}_{1}$ receptors. We identified residues where cysteine substitution (1) reduced currents and expression at the cell surface (R295C and R305C); however, mutants R295A and R305A (Ennion et al., 2000) had no effect on ATP potency, indicating that individual positive charges at these residues are not essential; (2) decreased ATP potency, 2-azido ATP binding, and modification by MTS reagents (K309C, R292C); (3) decreased ATP potency, modification by MTS reagents, a modest reduction in 2-azido ATP binding, and a reduction in Hill slope (N290C and F291C); or (4) had little or no effect on ATP potency and modification of amplitude by MTS reagents (D319C, G321C, A323C, and I328C).

Mutations in the extracellular domain could have effects on the binding of agonist to the receptor and/or the conformation change after agonist binding that controls activation of the channel (Colquhoun, 1998). The $\sim 200$-fold decrease in ATP potency at K309C is consistent with previous alanine-scanning mutagenesis of this residue in $\mathrm{P}_{2} \mathrm{X}_{1}$ (Ennion et al., 2000), $P 2 X_{2}$ (Jiang et al., 2000), and $\mathrm{P}_{2} \mathrm{X}_{7}$ (Worthington et al., 2002) receptors. Several features of this mutation are indicative of an effect on agonist binding. For the 200 -fold reduction in potency to result from a gating effect, this would require an $\sim 40,000$-fold reduction in gating constant with two molecules of ATP, and considerably higher if three bind to activate the channel. Because there is no reduction in the maximal response, gating would have to be highly efficacious at the WT receptor, which is unlikely given the low probability of single P2X channel openings (Ding and Sachs, 1999). Similarly, there is no detectable reduction in the Hill slope that would be expected if there were a change in gating. The $\sim 80 \%$ reduction in the amount of radiolabeled 2-azido ATP crosslinked to the mutant K309C receptor further supports a decrease in agonist binding. The rescue of potency with positively charged MTSEA suggests that K309 is involved in binding of the negatively charged phosphate group of the ATP molecule. Finally, the

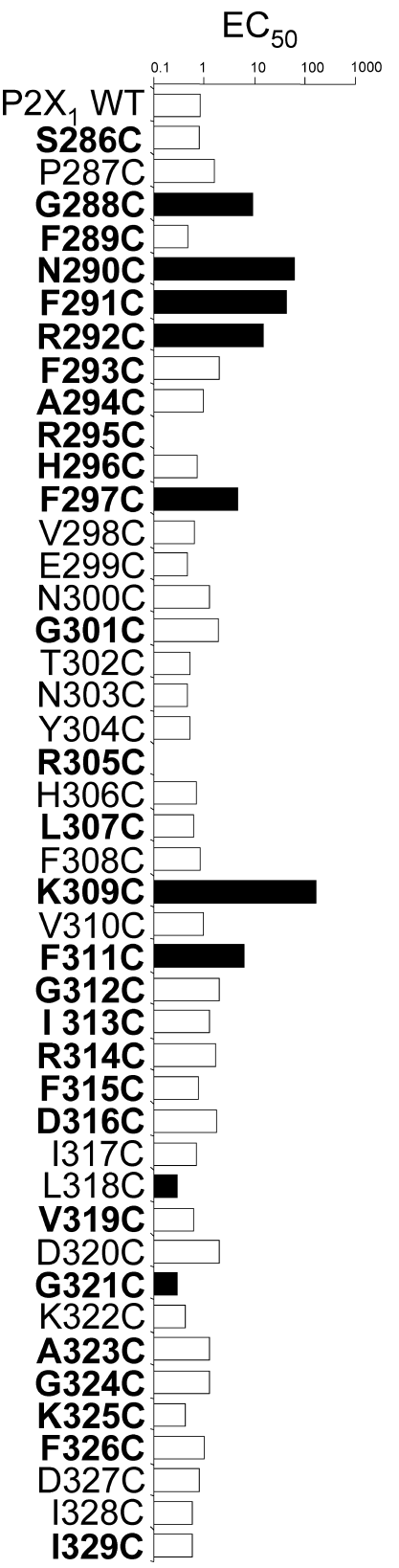

MTS

MTS MTSEA biotin MTSEA biotin $2^{\circ}$ (No $\left.\Delta \mathrm{EC}_{50}\right)$ $\left(\Delta \mathrm{EC}_{50}\right) \quad$ (+ Apyrase) $(+\mathrm{ATP})$
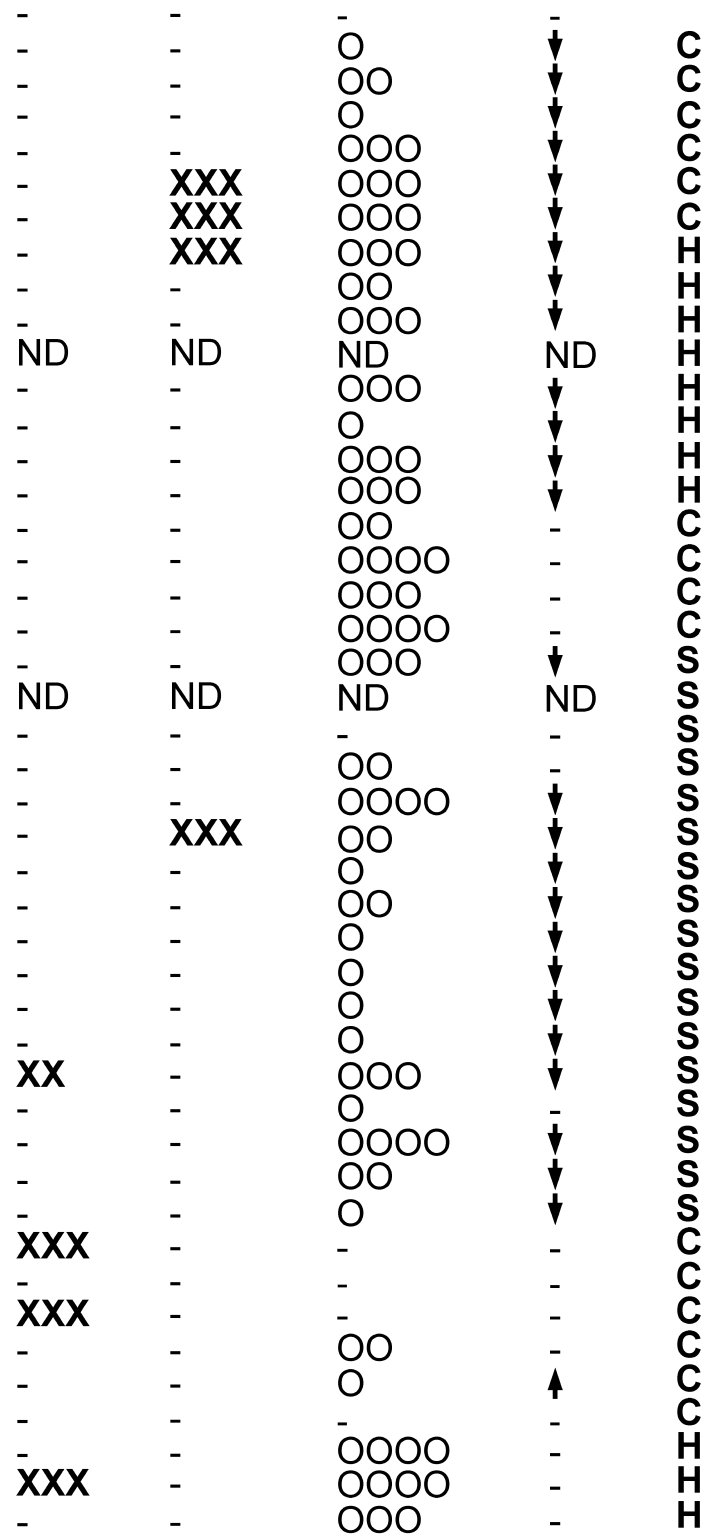

Figure 9. Summary of the effects of cysteine mutants on ATP potency, modification by MTS reagents, and MTSEA biotinylation. Mutants with a significantly changed $\mathrm{EC}_{50}$ compared with wild type are highlighted (black bar). Those mutants affected by MTS compounds are depicted as XX ( $25-50 \%$ change) and XXX (>50\% change) and are divided into mutants with ATP potency that was affected by MTS reagents and mutants that were not. Relative levels of MTSEA biotinylation are shown in the presence of apyrase: $\bigcirc$, one to two times threshold; $\bigcirc$, two to three times threshold; $\bigcirc \bigcirc$, three to four times threshold; $\bigcirc \bigcirc \bigcirc$, more than five times threshold. $n=3-5$. Significant decreases and increases in MTSEA biotinylation on ATP application are shown. ND, Not determined. Structural predictions for the region S286-1329 [PSIPRED (McGuffin et al., 2000)] are labeled C (coil), $H$ (helix), and S (strand). Residues in bold are conserved in at least five of the human P2X receptor subunits.

binding of MTSEA-biotin to the free cysteine residue introduced in the K309C mutant receptor was reduced by ATP application. Together, these results support the idea that lysine residue 309 forms part of the ATP binding site of the $\mathrm{P} 2 \mathrm{X}$ receptor.

The decreased ATP potency of the cysteine mutations N290C, F291C, and R292C is consistent with previous alanine-scanning mutagenesis studies (Ennion et al., 2000; Jiang et al., 2001; Roberts and Evans, 2004, 2006). The decrease in 2-azido ATP crosslinking and MTSEA biotinylation by ATP application indicate that these residues contribute to the ATP binding site. At N290C 
and R292C, ATP potency was further decreased by MTSEA or MTSES. In contrast, at F291C, ATP potency increased toward the WT levels after treatment with MTS reagents. The lack of discrimination between the effects of positive and negatively charged MTS compounds suggests that it is the localized disruption associated with binding of the MTS reagent, and not the charge, that modifies ATP potency. This indicates that it is unlikely that the positive charge of R292 coordinates binding of negatively charged phosphate on ATP, as suggested previously (Ennion et al., 2000; Vial et al., 2004b). The asparaginephenylalanine-arginine (NFR) motif is totally conserved in P2X receptors, and we have suggested that the aromatic phenylalanine is involved in binding of the adenine ring of ATP (Roberts and Evans, 2004); this is consistent with residues involved in ATP binding at other proteins (see below). In addition, the current results suggest that this motif is involved in agonist-induced conformational changes at the $\mathrm{P} 2 \mathrm{X}_{1}$ receptor.

A model of the C-terminal half of the extracellular segment of the $\mathrm{P}_{2} \mathrm{X}_{4}$ receptor was proposed based on similarity to the tRNA synthetases (Freist et al., 1998), and this has been supported by some mutagenesis studies (Yan et al., 2005). However, the residues suggested to form the $\mathrm{P}_{2} \mathrm{X}_{4}$ receptor binding site are different from those identified for the $\mathrm{P}_{2} \mathrm{X}_{1}$ receptor (Stojilkovic et al., 2005), suggesting that there may be differences in ATP action between $\mathrm{P} 2 \mathrm{X}$ receptor subunits.

Analysis of the local ATP binding environment in a number of crystal structures identified a similar pattern of residues involved in ATP binding to $\mathrm{P}_{2} \mathrm{X}_{1}$ receptors, as at rat synapsin II (Roberts et al., 2006) with an asparagine-aromatic-positive charge [asparagine-tryptophan-lysine (NWK)] motif with the aromatic group and positive charge coordinating the binding of the adenine and ribose groups of ATP [Protein Data Bank code li71 (Berman et al., 2000)]. An additional aromatic residue in synapsin II was associated with the adenine ring, and this is consistent with our previous work showing that F185 mutants decrease ATP potency (Roberts and Evans, 2004). Three positively charged lysine residues are also key components of the ATP binding environment at synapsin II, and these could correspond to K68, K70, and K309 that we have proposed to coordinate ATP binding (Ennion et al., 2000). The interface between subunits has been shown to be important for zinc binding in $\mathrm{P}_{2} \mathrm{X}_{2}$ receptors $(\mathrm{Na}-$ gaya et al., 2005) and ATP binding in $\mathrm{P}_{2} \mathrm{X}_{2 / 3}$ receptors (Wilkinson et al., 2006), and recent work on $\mathrm{P} 2 \mathrm{X}_{1}$ receptors shows that a disulphide bond can be formed between adjacent subunits of cysteine residues introduced at positions K68 and F291 (MarquezKlaka et al., 2007). Based on these findings, we suggest a revised working model of the binding site at the $\mathrm{P}_{2} \mathrm{X}_{1}$ receptor (Fig. 10).

MTSEA biotinylation has provided a useful assay to determine the surface accessibility of introduced cysteine residues. The lack (K322C) or threshold levels of MTSEA biotinylation (S286C, H306C, R314C, G321C, A323C, and F326C) suggests that these residues are either inaccessible $(\mathrm{K} 322 \mathrm{C})$ or give restricted access to MTSEA-biotin. In contrast, the majority of substituted cysteine residues showed MTSEA biotinylation with the relative levels giving an indication of relative accessibility. Of the MTSEAbiotinylated cysteine residues, only the N290F291R292 motif and K309 cysteine mutants showed changes in ATP potency after MTS application. MTSEA biotinylation at these residues was also reduced by ATP application. This would be consistent with ATP competing with the MTSEA-biotin for occupation of the agonist binding site and further supports the close association of the NFR motif and K309 with the ATP binding site.

The cysteine mutants D316C, G321C, A323C, and I328C were

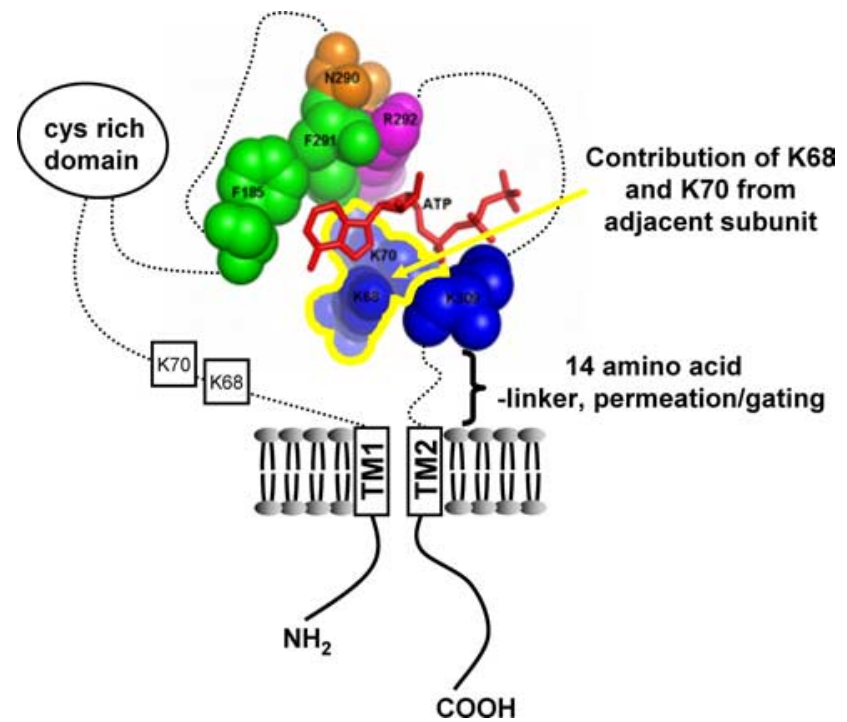

Figure 10. Model of ATP action at $P 2 X_{1}$ receptors. A schematic model of the $P 2 X_{1}$ receptor shows the two transmembrane domains (TM1 and TM2), intracellular $\mathrm{N}$ termini $\left(\mathrm{NH}_{2}\right)$ and $\mathrm{C}$ termini $(\mathrm{COOH})$, and the large extracellular ligand-binding loop. The P2X, receptor ATP-binding domain is based on mutagenesis data and similarity to the binding environment of ATP in the crystal structure of rat synapsin II [Protein Data Bank code 1i7l (Berman et al., 2000)]. Residues N290, F291, and R292 form a highly conserved motif across the P2X family, and mutagenesis studies confirm its role in ATP action (Ennion et al., 2000; Roberts and Evans, 2004; Roberts and Evans, 2006; present study). A similar motif (NWK) is found in rat synapsin Il and also forms part of the ATP binding environment. Positively charged lysine residue K309 is thought to interact with the negatively charged phosphates of ATP in the P2X $\mathrm{X}_{1}$ receptor, and lysine is also present in the ATP binding environment of rat synapsin II. There are two additional lysine residues in the local binding environment of synapsin II that could correspond to K68 and K70 identified previously as having a role in ATP action at P2X, receptors (Ennion et al., 2000). A recent study (Marquez-Klaka et al., 2007) indicates that these are likely to come from an adjacent subunit, and these residues are shown outlined in yellow. The cysteine-rich (cys rich) domain C117C165 is likely to contain three disulphide bonds: C117-C165, C126-C149, and C132-C159 (Ennion and Evans, 2002). The ATP binding region of the receptor is linked to opening of the channel by a 14 amino acid gating linker; mutagenesis of this region regulates the time course of the response with little or no effect on ATP potency.

sensitive to MTS reagents. At $\mathrm{P}_{2} \mathrm{X}_{2}$ receptors (Rassendren et al., 1997), MTS reagents had no effect on residues equivalent to the conserved residues $\mathrm{G} 321 \mathrm{C}$ and $\mathrm{A} 323 \mathrm{C}$, suggesting that constraints imposed by nonconserved parts of the receptor contributed to actions of MTS compounds at the $\mathrm{P} 2 \mathrm{X}_{1}$ receptor. At D316C and G321C, both MTSEA and MTSES inhibited responses indicating that introduction of bulk and not charge mediated the inhibition. At A323C, only negatively charged MTSES had an effect, and at I328C, only positively charged MTSEA was effective and suggests that the adjacent charged K322 and D327 residues contribute to efficacy of the MTS compounds at these residues. The MTSEA biotinylation of residues G324C, K325C, and D327C-I329C also gives an insight into the minimum dimensions and accessibility of this region of the channel (see above) that has been suggested to contribute to the outer vestibule of the channel pore (Rassendren et al., 1997).

The second transmembrane segment forms part of the P2X receptor channel pore and starts at about residue P330. Individual cysteine mutants in the region D316-I329 had little or no effect on ATP potency. MTS reagents modified responses at D316C, G321C, A323C, and I328C mutants with no effect on ATP potency; in addition, the mutants A323C and G324C showed a slowing in the time course of desensitization (Fig. 3). These results suggest that this region of the receptor does not contribute directly to ATP binding and reduction in amplitude of 
ATP responses at D316C, G321C, and I328C mutants by MTS compounds results from a decrease in ATP efficacy. This reduction in efficacy suggests that these residues are likely to be involved in regulation of ionic permeation or channel gating (Fig. 10). This is similar to the cys-loop ligand-gated ion channels and glutamate ion channels where the ligand binding site is distant from the transmembrane segments and residues close to the transmembrane segments link agonist binding to channel opening (Czajkowski, 2005) and supports recent work on $\mathrm{P}_{2} \mathrm{X}_{4}$ receptors (Yan et al., 2006).

In summary, this study has provided new insight into the molecular basis of ATP action at P2X receptors, the direct experimental evidence for the ATP binding site, and the accessibility of the C-terminal portion of the extracellular segment and has aided in the refining of a model of agonist action at this novel family of ATP-binding proteins.

\section{References}

Akabas MH, Stauffer DA, Xu M, Karlin A (1992) Acetylcholine receptor channel structure probed in cysteine-substitution mutants. Science 258:307-310.

Berman HM, Westbrook J, Feng Z, Gilliland G, Bhat TN, Weissig H, Shindyalov IN, Bourne PE (2000) The Protein Data Bank. Nucleic Acids Res 28:235-242.

Chessell IP, Hatcher JP, Bountra C, Michel AD, Hughes JP, Green P, Egerton J, Murfin M, Richardson J, Peck WL, Grahames CB, Casula MA, Yiangou Y, Birch R, Anand P, Buell GN (2005) Disruption of the P2X purinoceptor gene abolishes chronic inflammatory and neuropathic pain. Pain 114:386-396.

Clyne JD, Wang LF, Hume RI (2002) Mutational analysis of the conserved cysteines of the rat $\mathrm{P} 2 \mathrm{X}_{2}$ purinoceptor. J Neurosci 22:3873-3880.

Cockayne DA, Hamilton SG, Zhu Q-M, Dunn PM, Zhong Y, Novakovic S, Malmberg AB, Cain G, Berson A, Kassotakis L, Hedley L, Lachnit WG, Burnstock G, McMahon SB, Ford APDW (2000) Urinary bladder hyporeflexia and reduced pain-related behaviour in $\mathrm{P}_{2} \mathrm{X}_{3}$-deficient mice. Nature 407:1011-1015.

Colquhoun D (1998) Binding, gating, affinity and efficacy: the interpretation of structure- activity relationships for agonists and of the effects of mutating receptors. Br J Pharmacol 125:924-947.

Czajkowski C (2005) Neurobiology: triggers for channel opening. Nature 438:167-168.

Digby HR, Roberts JA, Sutcliffe, MJ, Evans RJ (2005) Contribution of conserved glycine residues to ATP action at human $\mathrm{P}_{2} \mathrm{X}_{1}$ receptors: mutagenesis indicates that the glycine at position 250 is important for channel function. J Neurochem 95:1746-1754.

Ding S, Sachs F (1999) Single channel properties of $\mathrm{P}_{2} \mathrm{X}_{2}$ purinoceptors. J Gen Physiol 113:695-720.

Egan TM, Haines WR, Voigt MM (1998) A domain contributing to the ion channel of ATP-gated $\mathrm{P} 2 \mathrm{X}_{2}$ receptors identified by the substituted cysteine accessibility method. J Neurosci 18:2350-2359.

Ennion S, Hagan S, Evans RJ (2000) The role of positively charged amino acids in ATP recognition by human $\mathrm{P}_{2} \mathrm{X}_{1}$ receptors. J Biol Chem 275:29361-29367.

Ennion SJ, Evans RJ (2002) Conserved cysteine residues in the extracellular loop of the human $\mathrm{P}_{2} \mathrm{X}_{1}$ receptor form disulfide bonds and are involved in receptor trafficking to the cell surface. Mol Pharmacol 61:303-311.

Fountain SJ, North RA (2006) A C-terminal lysine that controls human P2X ${ }_{4}$ receptor desensitization. J Biol Chem 281:15044-15049.

Freist W, Verhey JF, Stuhmer W, Gauss DH (1998) ATP binding site of P2X channel proteins: structural similarities with class II aminoacyl-tRNA synthetases. FEBS Lett 434:61-65.

Haines WR, Voigt MM, Migita K, Torres GE, Egan TE (2001) On the contribution of the first transmembrane domain to whole-cell current through an ATP-gated ionotropic P2X receptor. J Neurosci 21:5885-5892.

Jiang L-H, Rassendren F, Surprenant A, North RA (2000) Identification of amino acid residues contributing to the ATP binding site of a purinergic P2X receptor. J Biol Chem 275:34190-34196.

Jiang L-H, Rassendren F, Spelta V, Surprenant A, North RA (2001) Amino acid residues involved in gating identified in the first membranespanning domain of the rat ${\mathrm{P} 2 \mathrm{X}_{2}}_{2}$ receptor. J Biol Chem 276:14902-14908.

Jin R, Banke TG, Mayer ML, Traynelis SF, Gouaux E (2003) Structural basis for partial agonist action at ionotropic glutamate receptors. Nat Neurosci 6:803-810

Marquez-Klaka B, Rettinger J, Bhargava Y, Eisele T, Nicke A (2007) Identification of an intersubunit cross-link between substituted cysteine residues located in the putative ATP binding site of the $\mathrm{P}_{2} \mathrm{X}_{1}$ receptor. J Neurosci 27:1456-1466.

McGuffin LJ, Bryson K, Jones DT (2000) The PSIPRED protein structure prediction server. Bioinformatics 16:404-405.

Nagaya N, Tittle RK, Saar N, Dellal SS, Hume RI (2005) An intersubunit $\mathrm{Zn}^{2+}$ binding site in rat $\mathrm{P} 2 \mathrm{X}_{2}$ receptors. J Biol Chem 280:25982-25993.

North RA (2002) Molecular physiology of P2X receptors. Physiol Rev 82:1013-1067.

Rassendren F, Buell G, Newbolt A, North RA, Surprenant A (1997) Identification of amino acid residues contributing to the pore of a $\mathrm{P} 2 \mathrm{X}$ receptor. EMBO J 16:3446-3454.

Ren J, Bian X, DeVries M, Schnegelsberg B, Cockayne DA, Ford AP, Galligan JJ (2003) P2X $\mathrm{X}_{2}$ subunits contribute to fast synaptic excitation in myenteric neurons of the mouse small intestine. J Physiol (Lond) 552:809-821.

Rettinger J, Aschrafi A, Schmalzing G (2000) Roles of individual N-glycans for ATP potency and expression of the rat $\mathrm{P}_{2} \mathrm{X}_{1}$ receptor. J Biol Chem 275:33542-33547.

Roberts JA, Evans RJ (2004) ATP binding at human P2X $\mathrm{X}_{1}$ receptors: contribution of aromatic and basic amino acids revealed using mutagenesis and partial agonists. J Biol Chem 279:9043-9055.

Roberts JA, Evans RJ (2006) Contribution of conserved polar glutamine, asparagine and threonine residues and glycosylation to agonist action at human ${\mathrm{P} 2 X_{1}}_{1}$ receptors for ATP. J Neurochem 96:843-852.

Rong W, Gourine AV, Cockayne DA, Xiang Z, Ford AP, Spyer KM, Burnstock G (2003) Pivotal role of nucleotide P2X $\mathrm{X}_{2}$ receptor subunit of the ATPgated ion channel mediating ventilatory responses to hypoxia. J Neurosci 23:11315-11321.

Souslova V, Cesare P, Ding Y, Akopian AN, Stanfa L, Suzuki R, Carpenter K, Dickenson A, Boyce S, Hill R, Nebenius-Oosthuizen D, Smith AJH, Kidd EJ, Wood JN (2000) Warm-coding deficits and aberrant inflammatory pain in mice lacking $\mathrm{P}_{2} \mathrm{X}_{3}$ receptors. Nature 407:1015-1017.

Stojilkovic SS, Tomic M, He ML, Yan Z, Koshimizu TA, Zemkova H (2005) Molecular dissection of purinergic P2X receptor channels. Ann NY Acad Sci 1048:116-130.

Trapp S, Haider S, Jones P, Sansom MS, Ashcroft FM (2003) Identification of residues contributing to the ATP binding site of Kir6.2. EMBO J 22:2903-2912.

Tsuda M, Shigemoto-Mogami Y, Koizumi S, Mizokoshi A, Kohsaka S, Salter MW, Inoue K (2003) P2X P $_{4}$ receptors induced in spinal microglia gate tactile allodynia after nerve injury. Nature 424:778-783.

Vial C, Evans RJ (2002) P2X receptor-deficient mice establish the native P2X receptor and a $\mathrm{P}_{2} \mathrm{Y}_{6}$-like receptor in arteries. Mol Pharmacol 62:1438-1445.

Vial C, Tobin AB, Evans RJ (2004a) G-protein coupled receptor regulation

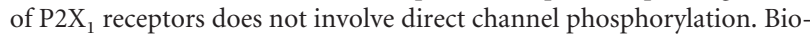
chem J 382:101-110.

Vial C, Roberts JA, Evans RJ (2004b) Molecular properties of ATP-gated P2X receptor ion channels. Trends Pharmacol Sci 25:487-493.

Walker JE, Saraste M, Runswick MJ, Gay NJ (1982) Distantly related sequences in the alpha- and beta-subunits of ATP synthase, myosin, kinases and other ATP requiring enzymes and a common nucleotide binding fold. EMBO J 1:945-951.

Wilkinson WJ, Jiang LH, Surprenant A, North RA (2006) Role of ectodomain lysines in the subunits of the heteromeric $\mathrm{P}_{2} \mathrm{X}_{2 / 3}$ receptor. Mol Pharmacol 67:1078-1088.

Worthington RA, Smart ML, Gu BJ, Williams DA, Petrou S, Wiley JS, Barden JA (2002) Point mutations confer loss of ATP-induced human P2X receptor function. FEBS Lett 512:43-46.

Yan Z, Liang Z, Tomic M, Obsil T, Stojilkovic SS (2005) Molecular determinants of the agonist binding domain of a P2X receptor channel. Mol Pharmacol 67:1078-1088.

Yan Z, Liang Z, Obsil T, Stojilkovic S (2006) Participation of the $\mathrm{Lys}^{313}-\mathrm{Ile}^{333}$ sequence of the purinergic $\mathrm{P} 2 \mathrm{X}_{4}$ receptor in agonist binding and transduction of signals to the channel gate. J Biol Chem 281:32649-32659. 